\title{
Levantamento de recursos e uma avaliação atual do Ensino de Astrofísica Estelar
}

\author{
Resource letter and an evaluation of the state-of-the-art of the teaching of Stellar Astrophysics \\ L. Paulucci回, J. F. Fornazari ${ }^{2}$, K. Brasil Neves ${ }^{3,4}$, J.E. Horvath ${ }^{*}[$ \\ ${ }^{1}$ Universidade Federal do ABC, 09210-170, Santo André, SP, Brasil. \\ ${ }^{2}$ Escola Estadual Dr. Heitor Penteado, 13465-060, Americana, SP, Brasil. \\ ${ }^{3}$ ETEC Campo Limpo Paulista, 13238-470, Campo Limpo Paulista, SP, Brasil. \\ ${ }^{4}$ Escola Estadual 15 de Outubro, 13230-330, Campo Limpo Paulista, SP, Brasil. \\ ${ }^{5}$ Universidade de São Paulo, Instituto de Astronomia, Geofísica e Ciências Atmosféricas, Departamento de Astronomia, \\ 05508-090, São Paulo, SP, Brasil.
}

Recebido em 19 de junho de 2021. Revisado em 28 de novembro de 2021. Aceito em 29 de novembro de 2021.

O conhecimento das estrelas avançou de maneira fundamental no último século, sendo que hoje podemos descrever os processos envolvidos em seu nascimento, evolução e morte. No entanto, a transposição do conhecimento científico estelar para a sala de aula não foi feita de maneira ampla ou tem sido feita em geral de forma fragmentada e parcial. Apresentamos aqui um levantamento sobre os trabalhos desenvolvidos nas últimas décadas para o ensino de Astrofísica Estelar (focado no material disponível em língua portuguesa) de modo a organizar e facilitar o trabalho da ampliação da abordagem deste tópico junto a estudantes, em particular no ensino básico, além de algumas sugestões de aplicações que poderão enriquecer o trabalho dos professores. Apresentamos também uma avaliação crítica do panorama dentro do ensino brasileiro.

Palavras-chave: Estrelas, Levantamento, Estado da Arte, Ensino.

Our knowledge about stars has fundamentally advanced over the last century and today we can describe the processes involved in their birth, evolution and death. However, the transposition of stellar scientific knowledge into the classroom has not been done in a broad way or has been done in general in a fragmented and partial way. We present here a survey of the work developed in recent decades for the teaching of Stellar Astrophysics (focused on the material available in Portuguese) in order to organize and facilitate the work of expanding the approach to this topic with students, particularly in basic education, in addition to some suggestions for applications that could enrich the work of teachers. We also present a critical assessment of the panorama within Brazilian education.

Keywords: Stars, Survey, State-of-the-art, Teaching.

\section{Introdução: Um Breve Resumo do Conhecimento das Estrelas ao Longo do Tempo}

\subsection{Da Antiguidade até o século 19}

A história do estudo das estrelas começa, como toda a Astronomia, em épocas pré-históricas por motivos principalmente religiosos e de organização das sociedades. Existem registros importantes no Crescente Fértil oriental onde as estrelas se misturam com uma visão mais ampla do Cosmos, e evidência de tabelas e estudos que utilizam a geometria para sistematizar o conhecimento das estrelas. Outras culturas também desenvolveram sua própria visão do céu, em particular das estrelas, brevemente descritas em Horvath (2019) [1].

Como quase toda a Ciência Ocidental, as bases do presente corpo de conhecimentos sobre as estrelas foram

\footnotetext{
* Endereço de correspondência: foton@iag.usp.br
}

estabelecidas na Grécia Antiga, onde a atitude racionalista enraizou-se e as causas físicas e lógicas tomaram conta das descrições do mundo natural [2].

$\mathrm{O}$ primeiro filósofo a imaginar a natureza das estrelas foi Anaximandro, de fato pensou que fossem buracos na abóbada que deixavam ver um fogo universal. Esta ideia da existência de uma esfera onde as estrelas (buracos ou objetos brilhantes) estavam atreladas é natural em qualquer modelo onde a Terra é o centro do Universo. De fato, Platão encomendou a seu discípulo Eudoxo o estudo deste modelo, o qual resultou em uma série de esferas concêntricas com velocidades de rotação diferentes para explicar o movimento dos planetas, e uma esfera externa onde as estrelas residiam, com um éter que se estendia infinitamente depois. Neste modelo a distância até a esfera "fixa" (as estrelas não se mexiam tal como os planetas o fazem, e daí sua denominação) era comparável à distância até o Sol (este mesmo um "planeta" no sentido grego). O Cosmos de Eudoxo tinha 


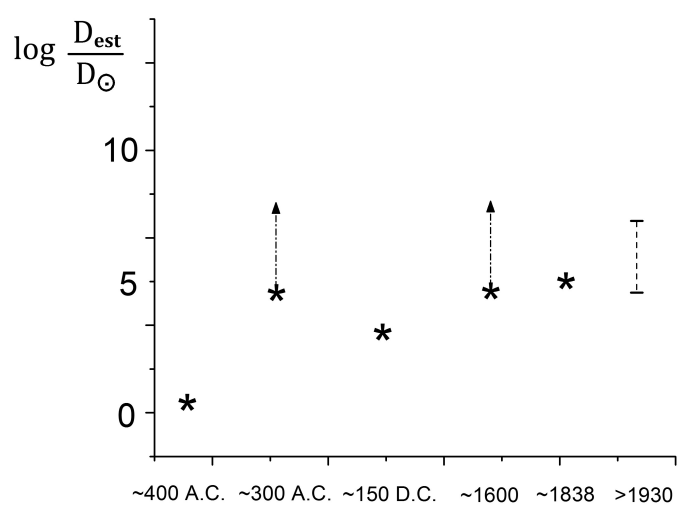

ano

Figura 1: O logaritmo da distância estimada até as estrelas através do tempo utilizando-se como referência a distância da Terra ao Sol. Os pontos correspondem, em sequência, aos modelos de Eudoxo ( 400 a.C.), Aristarco ( 300 a.C.), Ptolomeu ( 150 d.C.), Descartes e Bruno $(\sim 1600)$, Bessel ( 1838) e o intervalo de valores do "século 20" (>1930) (vide texto). A distância até as estrelas se multiplicou por um fator $>10000$ desde as ideias de Eudoxo até as medidas dos dias de hoje.

essa escala pequena (vide Figura 1 primeiro ponto à esquerda). Com Aristóteles o modelo ganhou aceitação geral (predominou por mais de 1 milênio) e uma separação drástica entre a natureza das estrelas e da Terra foi introduzida: Aristóteles pensava que estas estavam feitas de um material único chamado de quintessência, incognoscível à observação. Automaticamente o estudo das estrelas ficou relegado ao domínio das ideias e à filosofia pura, já que esta identificação impediu qualquer tentativa de aplicar leis da Física terrestre ao domínio estelar. Houve, contudo, uma voz dissonante no mundo grego a respeito das dimensões da Terra, o Sol e as distâncias até as estrelas (embora sua natureza e a existência de uma esfera não foram contestadas), a do astrônomo Aristarco de Samos. Aristarco pensava (como todos os gregos clássicos) que a Terra era uma esfera e identificou os eclipses com as sombras dos astros, o qual está basicamente correto. Na contramão do pensamento vigente, ele pensava que, na verdade, era a Terra que girava em torno do Sol e não o contrário. Sua determinação da distância e do raio do Sol e da Lua nas quadraturas foi basicamente correta, mas errou numericamente porque seus dados diretamente determinados (a olho nu) continham erros enormes. Mas independentemente disto, o modelo de Aristarco entrou em conflito com a observação da imobilidade das estrelas (além da rotação diária, atribuída à Terra): em um modelo heliocêntrico a ausência de paralaxe anual| $\left.\right|^{1}$

\footnotetext{
1 A paralaxe anual é a medida da variação angular da posição aparente de uma estrela no céu a partir de dois instantes de observação distantes de seis meses (linha de base para observação de $\sim 2$ vezes a distância Terra-Sol). Isso permite a estimativa da distância de um objeto, sendo que quanto mais distante, menor o ângulo de paralaxe medido.
}

implicava que a distância até a esfera das estrelas tinha que ser muitas ordens de grandeza maior que a aceita até então para não ser observada. Assim, a distância até as estrelas no modelo heliocêntrico tinha um limite inferior muito elevado (segundo valor desde a esquerda na Figura 11). Os modelos geocêntricos não apresentam este problema e as estrelas não mostram paralaxe anual porque estão sempre à mesma distância da Terra, numa distribuição esférica perfeita.

A síntese da Antiguidade grega clássica foi atingida uns séculos depois, no Almagesto de Ptolomeu, astrônomo da Biblioteca de Alexandria por volta do ano 150 d.C. Com a medida da circunferência da Terra por Eratóstenes (com resultado apenas cerca de $2 \%$ menor que o aceito atualmente), a distância até a esfera das estrelas fixas foi determinada por Ptolomeu em 20000 raios terrestres, ou algo como 2000 vezes a distância ao Sol (com a medida dessa época, esta última de fato ficou subestimada por um fator $\sim 20$ ). Esta escala de distância permaneceu por mais de 1200 anos como a verdadeira (terceiro ponto na Figura 1).

Somente no Renascimento houve uma reavaliação profunda destas ideias da Antiguidade. A Revolução Copernicana trouxe o Sol ao centro da consideração, mas ao contrário das ideias de Aristarco, foi coletando adesões e argumentos favoráveis. Com esta perspectiva, Descartes já considerou o Sol e as estrelas como sendo "da mesma" natureza. Por razões mais teológicas e filosóficas, Giordano Bruno tinha chegado à noção de um Universo infinito onde cada estrela era identificada como um "Sol", com seu próprio sistema planetário. Assim, para explicar as observações, a distância até as estrelas aumentou ordens de grandeza, ainda porém sem a possibilidade de se efetuar medidas concretas. Cabe apontar que o matemático e astrônomo indiano Aryabatha tinha formulado esta ideia 1 milênio antes, mas isto era desconhecido para Copérnico, Descartes e Bruno.

Com o desenvolvimento dos telescópios, a caça às distâncias estelares passou a um plano experimental. Galileu tentou estimar estas distâncias medindo os diâmetros estelares, mas conseguir determinar, a partir da imagem em sua luneta, o raio de uma estrela, mesmo das mais próximas, estava muitas ordens de grandeza além da sua capacidade tecnológica e só pôde ser atingido recentemente. Por sua vez, Newton tentou comparar o brilho de Sirius com o do Sol, e percebeu que bem poderia estar comparando coisas diferentes (ou seja, cogitou que as estrelas poderiam vir em muitas "variedades", fato confirmado pela moderna teoria da Evolução Estelar). Mas ignorando este fato, e fazendo a hipótese de que as estrelas são todas iguais (ou velaspadrão), já estudada no fim do século 17, é possível obter estimativas realistas das distâncias até as estrelas mais próximas 3. Contudo, a determinação direta das distâncias, e com ela a confirmação da natureza estelar, deveria aguardar mais um século a partir de Newton. 


\section{A medida da paralaxe estelar e o "Universo de Herschel"}

No começo do século 19 a determinação da distância até as estrelas foi um dos problemas mais importantes na consideração dos astrônomos. Um prêmio em moeda tinha sido estabelecido para quem apresentasse uma medida da paralaxe estelar, quantidade muito pequena que tinha escapado à deteç̧ão a olho nu na Antiguidade, mas que poderia confirmar a visão de Aristarco, Bruno e outros. O prêmio foi concedido à F. Bessel com a descoberta da paralaxe de 61 Cygni, a qual implicava uma distância de 11 anos-lut ${ }^{2}$ ou um fator centenas de vezes maior que o "esperado" no modelo Ptolomaico. O mundo das esferas com estrelas atreladas se desfez para dar passagem a um Cosmos gigantesco, possivelmente até infinito, com as estrelas como "outros sóis" como Bruno tinha imaginado.

Esta associação fundamental tinha sido observacionalmente indicada pelos trabalhos de Wollaston, que identificou linhas de absorção no espectro da luz do Sol, associadas a elementos químicos conhecidos, e Fraunhofer, que mostrou que as mesmas linhas apareciam nos espectros das estrelas. Tinham provado, assim, que a composição das estrelas é similar a do Sol, e que não estão feitas de nenhuma "quintessência". Conjuntamente com a determinação das distâncias, foi possível um estudo físico das estrelas usando as mesmas ferramentas que descrevem os objetos físicos na Terra.

Um segundo evento importante no século 19 foi a tentativa de W.Herschel de mapear com as estrelas todo o Cosmos conhecido, com o resultado da forma irregular da Figura 2. Herschel não conhecia a extinção da luz pela poeira cósmica e também estava quase um século adiantado para julgar a possível existência de unidades que hoje chamamos de galáxias [4]. De fato, a forma da nossa galáxia afetada pela extinção foi o que o Herschel realmente mediu. Porém, o filósofo I. Kant tinha levantado no fim do século 18 a ideia de "Universos-ilhas" separados por distâncias muito maiores que a distância às estrelas. Hoje entendemos isto como a existência de outras galáxias, mas até os trabalhos de E. Hubble era comum achar que a nossa galáxia era tudo o que existia, sem outras "fora" dela. A escala da galáxia tinha aumentado para vários milhares de anos-luz, e todas as estrelas que observamos individualmente estão na nossa galáxia (de fato observamos as mais próximas a olho nu, e algumas até dezenas de anos-luz com binóculos). Estas escalas, desde poucos anos luz até os confins da nossa galáxia, é o intervalo indicado com o intervalo vertical à direita na Figura 1 ("século 20").

\subsection{A Estrutura e Evolução Estelar no século 20 e sua projeção na Educação do século 21}

No fim do século 19 já existe um esforço considerável para classificar e depois modelar as estrelas. Os

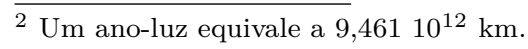

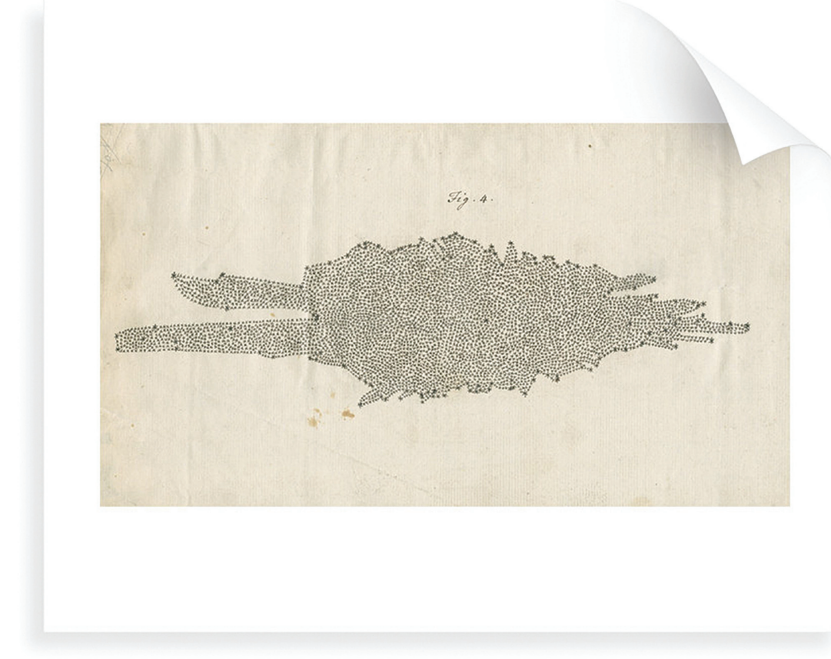

Figura 2: O Universo observado por W. Herschel, na imagem original da sua publicação. Hoje sabemos que as "irregularidades" na distribuição das estrelas são causadas pela extinção da luz pela poeira cósmica. O Sol é mais uma destas estrelas, que se encontram até distâncias de milhares de anos-luz. (Plate 8 figure 4 do trabalho "On the construction of the heavens", by William Herschel, Philosophical Transactions of the Royal Society, vol.75 (1785), pp. 213-266).

astrônomos E. Hertzprung e H.N. Russell criaram e fundamentaram o diagrama que leva seus nomes, onde expuseram que as estrelas poderiam mesmo ser muito diferentes entre si, sugerindo fases evolutivas posteriormente esclarecidas. Paralelamente, a classificação espectral de Harvard, sob responsabilidade de E. Pickering mas com o trabalho pioneiro de W. Fleming, C. Payne, H. Swan Leavitt e outras mulheres do grupo, foi desenvolvida e permitiu o aprofundamento nas características físicas das estrelas.

Já as ideias a respeito de estrutura (equilíbrio hidrostático, leis de conservação) foram estudadas por Lane e Emden, A. Eddington, E. Milne e outros. Embora a parte macroscópica da descrição das estrelas é decorrência da Física clássica dos fluidos, bem conhecida então, alguns aspectos cruciais não teriam sido possíveis sem a nova Física emergente, a Mecânica Quântica que não somente justificou as fontes de energia solar (a fusão estudada por Gamow, Bethe e outros), mas também abriu o caminho para o cálculo das opacidades estelares, fundamentais para entender o transporte de energia no interior e os próprios espectros estelares. Uma série de desenvolvimentos seguiram no estudo tanto dos estágios de formação, quanto no final da vida estelar (Chandrasekhar, Baade, Zwicky, Landau, Oppenheimer, Tolman, Volkoff e outros) também fortemente baseados na Mecânica Quântica e na Relatividade Geral. A meados do século 20 ou pouco mais, os fundamentos da atual teoria da Estrutura e Evolução Estelar estavam no lugar, embora os estudos em temas específicos continuassem a se desenvolver. 
Vemos assim a conveniência e oportunidade de introduzir temas das estrelas no Ensino Médio (ou até antes preferencialmente). Pode-se argumentar que a Evolução Estelar é a herdeira mais profícua da Física do século 20, fazendo deste tema um imperativo científico. Toda a estrutura e o ciclo da vida estelar estão fortemente fundamentados por modelos que aproveitam o conjunto de conhecimentos da "Física Moderna e Contemporânea" para construir um quadro coerente dos mesmos. A Astrofísica Estelar e a Física são totalmente simbióticas neste sentido, e se alavancaram mutuamente por muitas décadas. Assim, apresentar as estrelas desde pontos de vista histórico-filosófico e físico é totalmente coerente na Educação dos cidadãos do século 21. Como exatamente fazer isto é um problema complexo. Até agora vemos que há "retalhos" introduzidos aqui e lá nos currículos sugeridos, mas ainda falta uma unidade e uma interdisciplinaridade que está somente sugerida de forma incipiente. Seguem neste trabalho subsídios para o professor "preencher as lacunas" na medida da disponibilidade e oportunidade.

Ao abordar o tema de Astronomia em sala de aula, os alunos em geral demonstram interesse e se mostram motivados durante o período das aulas. O ensinoaprendizagem em Astronomia deve ser significativo e comprometido com o cotidiano e a visão básica dos estudantes. É constatado que ao incorporar um assunto mais "lúdico" na prática docente, o conhecimento se transforma em facilitador das áreas da Química, Física e Matemática, sendo assim, é possível apoiar o ensino-aprendizagem considerando estratégias de pesquisas como estímulos na construção do conhecimento, favorecendo o desenvolvimento de diferentes habilidades, tornando as aulas mais atrativas através da interdisciplinaridade dos conteúdos. É claro que este caráter lúdico é muito "menos leve" do que o esperado por eles, especialmente se o professor avança para uma verdadeira interdisciplinaridade quali-quantitativa. Daí a importância dos trabalhos acadêmicos aqui coletados, que contemplam conteúdos astronômicos reforçando informações e orientações educacionais desta vasta área de saberes em vários níveis. Os estudos permitem apresentar vários grandes temas da Astronomia e Astrofísica Estelar sem que eles percam empatia sensorial com a observação e análise destes fenômenos, que estão ligados aos pesquisadores, e eles podem traduzir como aprendizado ligado a pesquisa através de uma variedade de recursos tecnológicos. A utilização destes recursos desenvolve nos alunos criatividade, raciocínio crítico, aproximação com o método científico e as habilidades impostas para o desenvolvimento da pesquisa. Esta aproximação é um dos objetivos do presente texto.

\section{Metodologia}

Foram realizadas consultas a diferentes revistas, anais de conferências e repositórios de Teses e Dissertações disponíveis em língua portuguesa e alguns em língua espanhola, além de serem considerados livros e material em sites especializados. Aqueles que retornaram com contribuições específicas na temática do ensino relacionado a estrelas são apresentados nas Tabelas 1 e 2 Foram considerados apenas trabalhos completos. $\mathrm{O}$ número de trabalhos encontrados demonstra que o tópico desperta o interesse da comunidade, apesar de ainda ser relativamente pouco explorado e não fazer parte dos currículos escolares de forma explícita.

Os conteúdos específicos foram divididos em seis categorias, cobrindo toda a temática estelar. Estas categorias que ajudam a classificar os textos se mostram na Tabela 3 .

A Tabela 4 mostra a designação dos trabalhos selecionados a respeito do nível educacional ao qual estão dirigidos. Também aqui notamos a possibilidade de mais

Tabela 1: Levantamento bibliográfico realizado entre periódicos e contribuições em anais de eventos de educação em Física/ Astronomia, com o apontamento do período de cada publicação e do número de contribuições identificadas na temática estelar.

\begin{tabular}{|l|c|c|}
\hline Periódico & Período & $\begin{array}{c}\text { Quantidade de } \\
\text { artigos na } \\
\text { temática } \\
\text { estelar }\end{array}$ \\
\hline $\begin{array}{l}\text { Caderno Catarinense } \\
\text { de Ensino de Física e } \\
\text { Caderno Brasileiro de } \\
\text { Ensino de Física }\end{array}$ & $\begin{array}{c}1984-2002 \\
\text { e }\end{array}$ & 6 \\
\hline Ciência \& Educação & $1998-2021$ & \\
\hline $\begin{array}{l}\text { Revista Brasileira de } \\
\text { Ensino de Física } \\
\text { (RBEF) }\end{array}$ & $1979-2021$ & 30 \\
\hline $\begin{array}{l}\text { Revista Brasileira de } \\
\text { Pesquisa em Educação } \\
\text { em Ciências (RBPEC) }\end{array}$ & $2001-2021$ & \\
\hline $\begin{array}{l}\text { Revista Electrónica de } \\
\text { Enseñanza de las } \\
\text { Ciencias (REEC) }\end{array}$ & $2002-2021$ & 3 \\
\hline $\begin{array}{l}\text { Revista } \\
\text { Latino-Americana de } \\
\text { Educação em } \\
\text { Astronomia (RELEA) }\end{array}$ & $2004-2021$ & \\
\hline $\begin{array}{l}\text { Simpósio Nacional de } \\
\text { Ensino de Física } \\
\text { (SNEF) }\end{array}$ & $2005-2019$ & \\
\hline $\begin{array}{l}\text { Simpósio Nacional de } \\
\text { Ensino de Astronomia } \\
\text { (SNEA) }\end{array}$ & $2011-2019$ & 31 \\
\hline
\end{tabular}

Tabela 2: Levantamento bibliográfico realizado entre teses, dissertações e trabalhos de conclusão de cursos, com o apontamento do número de trabalhos identificados na temática estelar.

\begin{tabular}{|l|c|}
\hline Tipo de produção & $\begin{array}{c}\text { Quantidade de } \\
\text { trabalhos na } \\
\text { temática estelar }\end{array}$ \\
\hline Trabalhos de conclusão de curso & 7 \\
\hline Dissertações & 42 \\
\hline Teses & 3 \\
\hline
\end{tabular}


Tabela 3: Descrição dos conteúdos de Astrofísica estelar utilizados para a classificação dos trabalhos apresentados.

\begin{tabular}{|c|c|}
\hline Categoria & Conteúdos de Astrofísica Estelar \\
\hline E1 & $\begin{array}{l}\text { Observações básicas das estrelas } \\
\text { (magnitudes, cores, posições, etc.) e tipos/ } \\
\text { associações estelares (aglomerados, binárias, } \\
\text { etc.) }\end{array}$ \\
\hline E2 & Estrutura e composição das estrelas \\
\hline E3 & $\begin{array}{l}\text { Evolução das estrelas (incluindo } \\
\text { nucleossíntese) }\end{array}$ \\
\hline E4 & $\begin{array}{l}\text { As estrelas nas culturas (incluindo as } \\
\text { abordagens étnicas e constelações), aspectos } \\
\text { históricos, filosóficos e sócio-culturais das } \\
\text { estrelas }\end{array}$ \\
\hline E5 & Formação das estrelas, Meio Interestelar \\
\hline E6 & $\begin{array}{l}\text { Explosões estelares e remanescentes } \\
\text { (supernovas, anãs brancas, estrelas de } \\
\text { nêutrons, buracos negros) }\end{array}$ \\
\hline
\end{tabular}

Tabela 4: Descrição dos níveis educacionais utilizados na classificação dos trabalhos.

\begin{tabular}{|l|c|}
\hline Categoria & Nível Educacional \\
\hline EF & Ensino Fundamental \\
\hline EM & Ensino Médio \\
\hline ES & Ensino Superior \\
\hline ENF & Ensino Não Formal \\
\hline
\end{tabular}

de um nível educacional ser indicado, com a adaptação e ajuste necessários.

Finalmente na Tabela 5 são apresentados os classificadores empregados para foco temático educacional, desenvolvidos e adaptados a partir dos trabalhos de Megid Neto [5] e Bretones e Megid Neto [6]. O trabalho de Gonçalves, Bretones e Horvath [7] foi utilizado como modelo.

\section{Material Coletado}

Foram realizados levantamentos nos seguintes repositórios: Capes, USP, Unicamp, UFSCar, UFSC, Unesp, Google Acadêmico. O material coletado é apresentado e classificado a seguir. Somos cientes da existência de outras fontes de qualidade que ficaram de fora, já que é extremamente difícil realizar este levantamento de forma a buscar todas as possíveis fontes para prover uma listagem absolutamente completa. O número final de 117 artigos e 52 Teses/Dissertações/TCC foi complementado com alguns livros e sites disponíveis que oferecem cursos completos e uma abrangência de temas estelares. Recomendamos um exame e estudo de algumas destas referências gerais antes de decidir a respeito de como abordar os temas em sala de aula.

\subsection{Livros didáticos}

Alguns livros didáticos para os vários níveis de Educação têm sido publicados no país espaçadamente. Uma lista parcial compreende as obras de referência da Tabela 6 .
Tabela 5: Descrição dos focos temáticos educacionais.

\begin{tabular}{|c|c|}
\hline Categoria & Focos Temáticos Educacionais \\
\hline D1 & $\begin{array}{l}\text { Currículos e Programas: Pesquisa sobre } \\
\text { princípios, parâmetros, diretrizes e } \\
\text { fundamentos teórico-metodológicos em } \\
\text { relação às estrelas convencionalmente } \\
\text { atribuídos ao desenho curricular: objetivos } \\
\text { educacionais, conteúdos, estratégias, } \\
\text { avaliação, etc. Avaliação de propostas } \\
\text { curriculares ou projetos educacionais. } \\
\text { Proposição e desenvolvimento de programas } \\
\text { ou propostas alternativas de ensino para } \\
\text { uma série, disciplina, semestre letivo ou } \\
\text { ciclo escolar completo. }\end{array}$ \\
\hline D2 & $\begin{array}{l}\text { Formação e Características de Professores: } \\
\text { Trabalhos que abordem a formação inicial, } \\
\text { continuada e/ou permanente de professores } \\
\text { nos temas estelares, assim como monitores e } \\
\text { divulgadores em planetários, observatórios, } \\
\text { museus ou outros espaços não-escolares. }\end{array}$ \\
\hline D3 & $\begin{array}{l}\text { Conteúdo e Método: Estudos que se } \\
\text { dedicam à relação conteúdo-método no } \\
\text { ensino das estrelas. }\end{array}$ \\
\hline D4 & $\begin{array}{l}\text { Recursos Didáticos: Estudos de avaliação de } \\
\text { materiais ou recursos didáticos no ensino } \\
\text { das estrelas. }\end{array}$ \\
\hline D5 & $\begin{array}{l}\text { Características do Aprendente: Diagnóstico } \\
\text { dos aprendentes, sejam alunos ou público } \\
\text { não-escolar. Identificação (constatação) do } \\
\text { conhecimento prévio do aprendente, de sua } \\
\text { estrutura intelectual, modelos de } \\
\text { pensamento ou de suas concepções sobre as } \\
\text { estrelas. Estudos das atitudes e } \\
\text { características de um aprendente ou grupo } \\
\text { no contexto do processo de } \\
\text { ensino-aprendizagem. }\end{array}$ \\
\hline D6 & $\begin{array}{l}\text { História, Filosofia e Natureza da Ciência: } \\
\text { Trabalhos que buscaram incluir abordagens } \\
\text { de fatos históricos nos processos de } \\
\text { ensino-aprendizagem das estrelas. Trabalhos } \\
\text { que abordam aspectos relativos à filosofia ou } \\
\text { epistemologia da ciência, tais como: } \\
\text { concepção de ciência, de cientista, de } \\
\text { método(s) científico(s) por meio do estudo } \\
\text { das estrelas. Formulação e desenvolvimento } \\
\text { de teorias científicas, paradigmas e modelos } \\
\text { científicos, desde que voltados ao ensino. }\end{array}$ \\
\hline
\end{tabular}

\subsection{Sites}

Existem vários sites que oferecem material gratuito de qualidade, de grande utilidade na montagem de sequências didáticas já que contém muito material gráfico, animações e outros recursos. Uma seleção destes é

\section{INPE}

Curso "Introdução à Astronomia e Astrofísica", INPE http://www.inpe.br/ciaa2019/material-curso.php

Apostila:

http://www.inpe.br/ciaa2019/arquivos/pdfs/apostila_c iaa_2019_completa-compactado.pdf 
Tabela 6: Livros Didáticos, Paradidáticos e de Divulgação.

\begin{tabular}{|c|c|c|}
\hline Obra & $\begin{array}{l}\text { Cat./ } \\
\text { Foco }\end{array}$ & $\begin{array}{l}\text { N.Edu- } \\
\text { cacional }\end{array}$ \\
\hline $\begin{array}{l}\text { J.E. Horvath, } O A B C D d a \\
\text { Astronomia e Astrofísica, } \\
\text { (Ed. Livraria da Física, São } \\
\text { Paulo, 2008) .iag }\end{array}$ & $\begin{array}{l}\text { E1-E6/ } \\
\text { D4 }\end{array}$ & $\mathrm{EF}, \mathrm{EM}$ \\
\hline $\begin{array}{l}\text { J.E. Horvath, As estrelas na } \\
\text { sala de aula, (Ed. Livraria da } \\
\text { Física, São Paulo, 2019) }\end{array}$ & $\begin{array}{l}\text { E1-E6/ } \\
\text { D4 }\end{array}$ & EM \\
\hline $\begin{array}{l}\text { J.E. Horvath e Custódio, } \\
\text { P.S., Os buracos negros na } \\
\text { ciência atual: um brevíssimo } \\
\text { manual introdutório (Ed. } \\
\text { Livraria da Física, São Paulo, } \\
2013 \text { ) }\end{array}$ & $\mathrm{E} 6, \mathrm{D} 4$ & $\begin{array}{l}\text { EM, ES, } \\
\text { ENF }\end{array}$ \\
\hline $\begin{array}{l}\text { S.M.M. Viegas, Entre estrelas } \\
\text { e galáxias, (Ed. Terceiro } \\
\text { Nome, São Paulo, 2011) }\end{array}$ & $\begin{array}{l}\text { E1, E5/ } \\
\text { D4 }\end{array}$ & $\begin{array}{l}\text { EM, } \\
\text { ENF }\end{array}$ \\
\hline $\begin{array}{l}\text { S.M.M. Viegas e F. de } \\
\text { Oliveira, Descobrindo o } \\
\text { Universo, (Ed. Edusp, São } \\
\text { Paulo, 2004) }\end{array}$ & $\begin{array}{l}\text { E1-E6/ } \\
\text { D4 }\end{array}$ & $\begin{array}{l}\text { EM, } \\
\text { ENF }\end{array}$ \\
\hline $\begin{array}{l}\text { K.C. Chung, Vamos falar de } \\
\text { Estrelas? Rio de Janeiro: } \\
\text { Universidade do Estado do } \\
\text { Rio de Janeiro }(2000) /\end{array}$ & $\begin{array}{l}\text { E1-E6/ } \\
\text { D4 }\end{array}$ & EM, ES \\
\hline $\begin{array}{l}\text { S.O. Kepler e M.F.O. } \\
\text { Saraiva, Astronomia e } \\
\text { Astrofísica (Ed. Livraria da } \\
\text { Física, São Paulo, 2004.) }\end{array}$ & $\begin{array}{l}\text { E1-E6, } \\
\text { D4 }\end{array}$ & $\mathrm{ES}$ \\
\hline $\begin{array}{l}\text { L.I. Arany-Prado, À luz das } \\
\text { estrelas (Ed. DP \& A Ltda, } \\
\text { Rio de Janeiro, 2006) }\end{array}$ & $\begin{array}{l}\text { E1-E6, } \\
\text { D4 }\end{array}$ & EM \\
\hline $\begin{array}{l}\text { T.A. Napoleão, Guia de } \\
\text { estudos "Astrofísica Estelar } \\
\text { para o Ensino Médio". } \\
\text { http://www.astro.iag.usp.br } \\
\text { / guia/ }\end{array}$ & $\begin{array}{l}\mathrm{E} 1, \mathrm{E} 2, \\
\mathrm{E} 3 / \mathrm{D} 4\end{array}$ & EM \\
\hline
\end{tabular}

\section{IAG-USP}

Curso completo com 66 vídeo-aulas em duas partes

AGA 0100 - Astronomia: Uma Visão Geral I

https://www.youtube.com/playlist?list=PLxI8Can9y AHd7kUPviBHxr-49QEl7PRXR

AGA 0100 - Astronomia: Uma Visão Geral II

https://www.youtube.com/playlist?list=PLxI8Can9y

AHfJ2sGxMii8mJ6maoCj9AtU

\section{UFSC}

Astrofísica para todos - UFSC

https://astrofisica.ufsc.br/

\section{$\mathrm{ON}$}

Apostila do Curso a Distância https://app.box.com/s/zq0d8il4ctnpz4o51gzn

\section{UFRGS}

Material didático e hipertextos http://www.if.ufrgs.br/ast/hipertextos.html http://www.if.ufrgs.br/ fatima/faad.htm

J.G. Hetem Observando estrelas jovens: conheça o ciclo de vida das estrelas

Ciência Hoje, 2000. Disponível em <http://chc.cienciah oje.uol.com.br>. Acesso em Junho 10/2021

\subsection{Artigos, Teses e Dissertações}

De forma mais específica, em cada uma das categorias indicamos alguns artigos/Teses/Dissertações particularmente úteis para conhecimento do professor na sua tarefa de montar uma Sequência Didática adequada às suas necessidades. Estas sugestões são brevemente justificadas para facilitar a escolha preliminar, mas cada caso pode merecer uma avaliação diferente, necessitando um exame de outras fontes. Seguem as listas com uma breve introdução que apontam pontos importantes para o professor, e uma avaliação e justificativa dos trabalhos que mereceram destaque. A relação completa dos trabalhos levantados em cada categoria está no Apêndice A

E1. Observações básicas das estrelas (magnitudes, cores, posições, etc.) e tipos/associações estelares (aglomerados, binárias, etc.)

O conhecimento das estrelas começa de fato com a observação básica, e isto resulta muito importante e estimulante para os alunos. Idealmente o professor de Ciências deveria ser capaz de introduzir e discutir vínculos integradores com a Astronomia atual, de tal forma que os alunos possam enxergar no ensino temáticas e materiais que aprimoram o conhecimento, auxiliando no despertar científico e fortalecendo sua divulgação. Existe uma espécie de "barreira epistemológica" entre a Astronomia do Sistema Solar, tema muito recorrente presente no currículo escolar, e as estrelas, no sentido de que vários levantamentos mostram um desconhecimento bem maior e concepções alternativas múltiplas no segundo caso. Portanto, é imprescindível começar trazendo as estrelas para o âmbito do empirismo, antes mesmo de discutir sua natureza e os fenômenos físicos a elas associados.

Lista de trabalhos sugeridos e material que aborda diversas questões neste assunto:

1. Uma proposta para o ensino da Astronomia e Astrofísica estelares no Ensino Médio. J.E. Horvath, RBEF 35, no.4, 1 (2013) E1, E2, E3/ D1, D3/ EM - Material poderá ser abordado em conjunto com o material da primeira série do Ensino Médio no Estado de São Paulo (uma vez que o tema de estrelas já está aí presente mas, sem aprofundamento), utilizando dessa forma como recurso metodológico para introduzir a física das observações e temas, explicando a fenomenologia do que ocorre 
evitando apresentar apenas o fenômeno sem maior ponderação e explicação.

2. O Diagrama HR como ideia-âncora para a organização prévia no Ensino de Astronomia e Física. F. Duarte Calado e H. Luz Oliveira. Atas do XXI SNEF (Uberlândia, 2015) E1, E2, E3/ D1, D2/ EM - Material que tem potencial para ser aplicado como itinerário formativo no novo Ensino Médio, a ideia âncora que propicia o desenvolvimento das demais disciplinas no currículo de forma interdisciplinar ou possibilidade transdisciplinar. Pode-se relacionar além das Ciências da Natureza e da Matemática, as Ciências Humanas. De fato, a classificação de animais, elementos químicos etc. é um passo importante para sistematizar o conhecimento acumulado, e os esquemas decorrentes (árvore da Vida, Tabela Periódica etc.) são considerados fundamentais para esta organização. O professor poderá repensar e desenvolver estas articulações com seus pares.

3. Uma nova abordagem de conceitos de Fúsica e Astronomia a partir do diagrama HR. A.A. Pereira Beloni. (Dissertação. Universidade Federal de Mato Grosso. 2016) E1, E2, E3/ D1, D3, D4/ EM - Material que pode ser trabalhado sob forma de apresentação em Feira de Ciências para propiciar aos alunos a compreensão do tema, além de fornecer a introdução para a Astrofísica presente nas relações e interligações com a Química e Biologia, podendo ser um projeto para a área de ciências da natureza.

A relação completa de outros artigos levantados na Categoria E1 encontra-se na Tabela A1 do Apêndice A.

\section{E2: Estrutura e composição das estrelas}

Enquanto o item E1 pertence principalmente ao domínio do empirismo, explorar com os estudantes a estrutura e a composição das estrelas propicia o debate não só de aspectos históricos e filosóficos, mas também físicos (vide Introdução). Temos evidências para afirmar (Bastos da Silva, Tabela A1 \#128") que a passagem das observações básicas aos modelos que explicam as características das estrelas é difícil nas abordagens didáticas, causando nos alunos a proliferação de concepções alternativas e uma falta de percepção geral do que quer dizer um "modelo" físico das estrelas. Esta relação é fundamental em Ciências, já que o cientista pensa muito mais em termos dos modelos do que em termos positivistas do tipo "acumulativo". Este tipo de falta de conexão entre os dados/observações e o quadro físico que pretende explicá-los se estende a outros assuntos importantes em Ciências (por exemplo, a evolução do Universo, a estrutura da Terra, etc.), e resulta portanto geral e fundamental para qualquer abordagem, começando no Ensino Fundamental com as devidas ressalvas.
A lista de trabalhos sugeridos e material que aborda diversas questões neste assunto, destacamos aqui dois de particular utilidade:

- Origem, evolução e morte das estrelas: uma Sequência Didática para os alunos do Ensino Médio. W. Fernandes da Silva, Tabela A1 \#110. O trabalho de Fernandes da Silva enfatiza a estrutura estelar e a Física envolvida com a intenção de justificar e expor na sua totalidade esta relação, de grande interesse para colocar a seguir a ideia de evolução nos alunos.

- A contextualização da Estrutura e Evolução Estelar no ensino da Termodinâmica como ferramenta motivadora dos alunos. J. Torres Lima e D.B. Pavani. Atas do III SNEA (Curitiba, 2014) E2, E3/ D4, D5/ EM - Material que pode ser inserido em aulas de Física no Ensino Médio, conciliando a Termodinâmica que está pouco abordada no currículo do Estado de São Paulo, sendo contextualizada com a evolução estelar que já vem sendo abordada no currículo do Ensino Fundamental.

A relação completa de outros artigos levantados na Categoria E2 encontra-se na Tabela A2 do Apêndice A

\section{E3: Evolução das estrelas (incluindo nucle- ossíntese)}

A categoria E3 adiciona ainda uma dimensão temporal (evolutiva) ao problema das estrelas. A própria ideia de nascimento, vida e morte estelares não está presente no rol de conhecimentos da maior parte dos alunos, ou possivelmente está mas de forma fragmentada e inconsistente. Enxergar a classificação do Diagrama HR como decorrência das mudanças ao longo da vida estelar é um objetivo importante, que liga indissoluvelmente os itens E1 e E2 anteriores, e coloca as estrelas em uma categoria de objetos dinâmicos, com transformações importantes, desfazendo a visão de imutabilidade que ainda paira na cognição de muitos alunos.

- M.B. da Fonseca Vieira, Tabela A2 \#122. A Dissertação de Fonseca Vieira propõe uma sequência integrada com a Física para descrever as causas da Evolução Estelar como decorrência das mudanças no interior, avaliando até que ponto os alunos conseguem sintetizar os temas e reforçar mutuamente sua compreensão.

- Um jogo de RPG para ensinar sobre Astrofísica. F.L. Rommel e V. Scheibel. Atas do XXII SNEF. (São Carlos, 2017) E3/ D3, D4/ EM. Material indicado para uso em sala de aula de ensino fundamental, precisamente dos anos finais, com o uso de jogo como meio de acesso a informações e interação social. Esta abordagem favorece o desenvolvimento de estudantes argumentativos e corrobora com a função mediadora do professor visando coletar evidências de desenvolvimento de procedimentos e atitudes nos participantes do jogo. 
A relação completa de outros artigos levantados na Categoria E3 encontra-se na Tabela A3 do Apêndice A

E4: As estrelas nas culturas (incluindo as abordagens étnicas e constelações), aspectos históricos, filosóficos e socio-culturais das estrelas

Esta categoria é muito ampla e particularmente interessante para trabalhar em sala de aula como tema transversal, já que possui desdobramentos vários para outras disciplinas. Como descrito na Introdução, a visão das estrelas foi construída historicamente nas ciências, e também com a realidade e a cosmovisão de outros povos afro-americanos, indígenas e de cultura não-europeia em geral. A BNCC recomenda a apresentação destas visões da natureza, embora sejam em grande medida incomensuráveis com a tradição racionalista ocidental. Assim, deve-se distinguir uma discussão históricofilosófica dentro do marco racionalista da escola e uma apresentação de visões alternativas que não são pautadas por estes paradigmas, tal como o trabalho recomendado do autor L.C. Jafelice (Tabela A4 \#143). Os trabalhos que destacamos são

- A observação do céu: da História para entender o Ensino dentro da Teoria Histórico-Cultural. T.F. Genzini de Carvalho e J. Lopes de Almeida Pacca, Tabela A1 \#16. Avaliação da contribuição à significação social e humana utilizando uma atividade (no sentido da Teoria de Leontiev) e as ideias de Vigotsky como marco teórico, de interesse para uma abordagem em sala de aula, esta última a ser definida.

- Uma proposta de discussão de controvérsias históricas e epistemológicas acerca da Evolução Estelar para o Ensino Médio. B. Lopes da Costa, F. Polati e M.P. Allen. Atas do V SNEA (Londrina, 2018) E4/ D3, D6/ EM. Discussão socrática do processo de construção do conhecimento científico, em particular, das características físicas dos objetos "escuros", mostrando os aspectos mais escondidos do trabalho científico no contexto.

- Astronomia Cultural nos ensinos Fundamental e Médio. L.C. Jafelice. RELEA 19, 57 (2015) E4/ D1, D3/ EF, EM. Abordagem genuinamente horizontal da interculturalidade, com imersão no universo do pensamento indígena e de outras minorias. Cobre muito do que normalmente é tratado superficialmente (e com uma perspectiva reitora) nos currículos recomendados.

- A construção de conceitos sobre a pequenez humana: Astronomia em aulas de Filosofia no Ensino Médio. C. A. do Nascimento e P.S. Bretones. Atas do V SNEA (Londrina, 2018) E4/ D1, D6/ EM. Mergulho nas implicações filosóficas do conhecimento das escalas e natureza das estrelas e do Cosmos, com enquadramento psicossocial da humanidade no contexto astronômico.
A relação completa de outros artigos levantados na Categoria E4 encontra-se na Tabela A4 do Apêndice A.

\section{E5: Formação das estrelas, Meio Interestelar}

Os avanços nas técnicas observacionais do início do século 20 proporcionaram uma compreensão cada vez maior daquilo que existe entre as estrelas, o meio interestelar. Foi possível determinar que a matéria interestelar é formada por gás e poeira, apresentando-se tipicamente na forma de nuvens, compostas predominantemente por hidrogênio molecular, neutro ou ionizado. Com a determinação de que as estrelas não eram compostas por uma "quintessência" mas sim em sua maior parte por hidrogênio, um caminho natural era associar essas nuvens com os berçários estelares, hoje bem identificados e estudados.

O processo de formação das estrelas e meio interestelar é hoje bem compreendido e medido podendo, naturalmente, ser levado à sala de aula em conexão com diferentes conteúdos de Física e também em abordagens interdisciplinares (vide, por exemplo, T. C. Caetano e G. Hickel, Tabela A1 \#6). Os trabalhos de destaque:

- Formação e evolução estelar como uma proposta de contextualização para o ensino de Termodinâmica no Ensino Médio. R. da Silva Rosa Rodrigues, Tabela A2 \#129. Utiliza este tópico para abordar a Termodinâmica no Ensino Médio, com especial atenção à transformação de energia potencial gravitacional em energia térmica durante o processo de contração das nuvens moleculares, além da emissão de radiação proveniente das superfícies estelares.

- Análise qualitativa de uma sequência didática (SD): Ensino de Astrofísica Estelar para alunos do Ensino Médio. K. Brasil Neves, Tabela A2 \#123. A autora utiliza a Astronomia para abordar tópicos relativos à gravitação, ondas e Física Moderna. Em particular, dedica-se a descrever o teorema do Virial e o equilíbrio hidrostático, fundamentais no processo de formação e evolução estelares.

- O Sol: Uma proposta de Ensino. I. Gomes Varella, Tabela A1 \#103. Este trabalho apresenta uma extensa abordagem que alia a Astronomia a disciplinas como a Biologia, mas também Meteorologia e Geologia, tendo relatado o despertar de grande interesse pelos alunos do Ensino Básico nas atividades interdisciplinares realizadas.

A relação completa de outros artigos levantados na Categoria E5 encontra-se na Tabela A5 do Apêndice A.

E6: Explosões estelares e remanescentes (supernovas, anãs brancas, estrelas de nêutrons, buracos negros)

Supernovas são eventos de ejeção de matéria envolvendo a formação de estrelas de nêutrons/buracos negros ou anãs brancas em interação. Os objetos compactos 
(anãs brancas, estrelas de nêutrons e buracos negros) constituem os estágios finais na evolução das estrelas, e representam estados extremos da matéria, proporcionando condições para eventos de alta energia. As abordagens apresentadas descrevem o processo de evolução como um todo e características básicas dos objetos compactos, como, por exemplo, em Tabela A1 \#109, Tabela A2 \#115, \#123 e \#128, ou escolhem o aprofundamento em um dos tópicos. Neste sentido, as abordagens específicas envolvendo supernovas, anãs brancas e estrelas de nêutrons são muito menos frequentes que as que envolvem buracos negros. Em algumas propostas, os buracos negros são o foco e se pretende explicar aspectos que os distinguem de outros objetos.

- Michell, Laplace e as estrelas negras: uma abordagem para professores do Ensino Médio. R.R. Machado e A.C. Tort, RBEF 38, 0017 (2016) E6/ D6 / EM. Neste artigo ganham destaque os aspectos históricos para a proposta da existência de um objeto de tamanha gravidade, capaz de aprisionar até raios luminosos.

- Astronomia no Ensino Médio: uma abordagem simplificada a partir da teoria da Relatividade Geral. R. V. Lessa do Couto. (Dissertação. Universidade de Brasília. 2020) E6 / D1, D3 / EM. Proposta de intervenção didática apoiada sobre a teoria da aprendizagem significativa de Ausubel e o programa de filosofia para crianças e adolescentes de Matthew Lipman no Ensino Médio com abordagem dedicada aos buracos negros sob o ponto de vista da Relatividade Geral.

- Os conceitos da Teoria da Relatividade com utilização do Ensino Sob Medida. G. H. Garcia. (Dissertação. Universidade Federal do ABC. 2019) E6/ D1, D3/ EM. Proposta ancorada na metodologia de ensino-aprendizagem do ensino sob medida, abordando a temática da teoria da relatividade e buracos negros, com extenso material de apoio para aprofundamento do professor no tópico.

- A utilização do filme Interestelar para o ensino de Fúsica Moderna no Ensino Médio. L.F. de Melo, D.F. Rodrigues, R.C. de Castro, C. J. Ferreira, A.N.S. Farias, C. de F. B. de Oliveira e T.S.O. Alvez. Atas do XXII SNEF (São Carlos, 2017) E6/ D3, D4/ EM. Este trabalho utiliza a temática da gravitação como foco, com buracos negros ilustrando conceitos dentro da Relatividade Geral, valendo-se de recursos audiovisuais na forma do filme Interestelar, para discutir a gravitação.

A relação completa de outros artigos levantados na Categoria E6 encontra-se na Tabela A6 do Apêndice A.

\section{Análise da Amostra}

A amostra coletada foi analisada desde os pontos de vista quantitativo e qualitativo. Cabe esclarecer que os
Tabela 7: Distribuição das 169 pesquisas por conteúdo.

\begin{tabular}{|l|c|c|}
\hline Categoria & No. & $\%$ \\
\hline E1 & 111 & 66 \\
E2 & 59 & 35 \\
E3 & 48 & 28 \\
E4 & 40 & 24 \\
E5 & 20 & 11 \\
E6 & 30 & 18 \\
\hline
\end{tabular}

conteúdos específicos foram classificados como "Recursos Didáticos", e não separados como feito no trabalho da Ref. [7. A distribuição da amostra por conteúdo é mostrada na Tabela 7. Note-se que alguns trabalhos estão incluídos em mais de uma categoria.

Observa-se que a distribuição por temas é muito díspar, $2 / 3$ dos trabalhos se referem aos aspectos básicos das estrelas e muito poucos a sua formação (11\%) ou seu fim $(18 \%)$. Existe uma notória carência de material variado particularmente nestes últimos temas, que requerem, desde um ponto de vista físico, um maior conhecimento. Somente como exemplo, é bem incomum encontrar professores que conheçam a existência de estados densos da matéria que não são um gás ideal, onde a Mecânica Quântica aparece em toda sua dimensão. Assim, expor e explicar anãs brancas ou estrelas de nêutrons se apresenta como impossível, e em geral estes temas são colocados de lado. Já os buracos negros aparecem com maior frequência, mas em boa medida por causa de uma superexposição midiática que desperta a curiosidade dos alunos e força alguma referência a eles. Isto não implica em absoluto que o básico destes "cadáveres estelares" seja compreendido e assimilado, e menos ainda desde um ponto de vista astronômico/evolutivo. Para piorar, uma boa dose de "mistério" e insondabilidade é adicionada ao tema, e nunca paira a noção de serem mais um objeto comum do zoológico estelar, abordado e pesquisado pelos astrônomos profissionais de forma cotidiana.

Em resumo, é notável a grande concentração de trabalhos nos tópicos E1 (observações básicas das estrelas e tipos/associações estelares) e E2 (estrutura e composição das estrelas) enquanto que os tópicos E5 (formação das estrelas e meio interestelar) e E6 (explosões estelares e remanescentes) contam com poucas abordagens (um destaque para este último se dá pelo interesse em buracos negros, como já descrevemos, e pode ser verificado pelo número de trabalhos específicos na listagem). Somente 2 trabalhos em E5 e 4 em E6 foram dirigidos ao $\mathrm{EF}$, onde seria ideal a introdução com força da ideia de evolução (nascimento, vida e morte) das estrelas (embora há na escola uma ênfase enorme nos "ciclos de vida" das plantas e outros). Batista, Silva e Silva [8] já apontavam para este fato ao analisar os trabalhos do ENPEC sobre ensino de Astronomia, com grande concentração em temas relativos ao sistema Terra-SolLua e posicionamento das estrelas, no lugar de temáticas associadas à Astrofísica. 
Tabela 8: Distribuição das 169 pesquisas por nível educacional.

\begin{tabular}{|l|c|c|}
\hline Nível & No. & $\%$ \\
\hline EF & 44 & 26 \\
EM & 128 & 75 \\
ES & 43 & 25 \\
ENF & 14 & 8 \\
\hline
\end{tabular}

\section{Histograma Temporal}

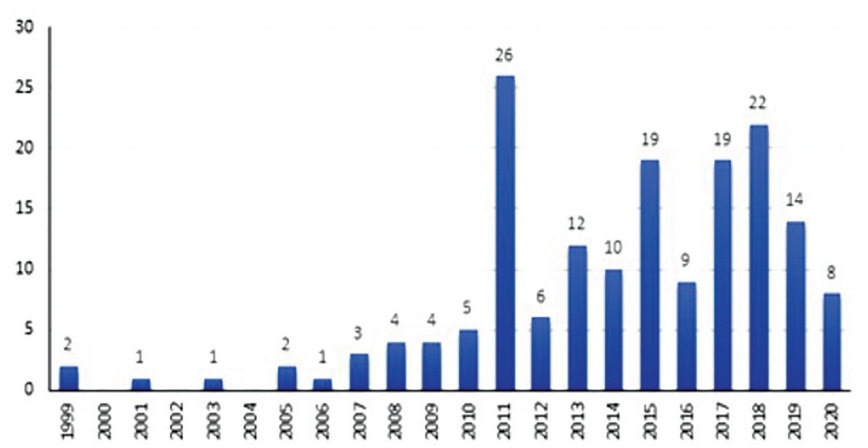

Figura 3: Os trabalhos publicados por ano de aparecimento.

Na Tabela 8 vemos justamente a distribuição das abordagens didáticas por nível educacional. Estas percentagens estão em linha com o que acontece com outros temas de Física Moderna e Contemporânea e Astrofísica/Cosmologia, 75\% dos trabalhos são dirigidos ao Ensino Médio. Uma constatação adicional é a de que o número de abordagens sobre Evolução Estelar é muito reduzido, em particular para o Ensino Fundamental onde somente 5 trabalhos foram identificados.

Ao observamos a distribuição temporal na publicação dos trabalhos selecionados nesta amostra (Figura 3), notamos um máximo proeminente e súbito no ano de 2011, seguido de um aumento consistente da média de trabalhos nos anos seguintes. O máximo parece estar relacionado à realização da Assembleia Geral da União Astronômica Internacional, que levou à realização, por exemplo, do primeiro SNEA (Simpósio Nacional de Educação em Astronomia) em 2011 na UNIRIO, como uma reunião satélite. Deste modo, a realização desta importante reunião da comunidade astronômica internacional no Brasil foi também bem direcionada como um incentivo aos trabalhos de divulgação e ensino do tópico no país. Já a tendência de aumento dos trabalhos nos anos seguintes apresenta correlação com a criação de mestrados profissionais na área: Mestrado Profissional em Ensino de Astronomia (MPEA), no IAG-USP, Mestrado Profissional em Astronomia, na UEFS, e Mestrado Nacional Profissional em Ensino de Física (MNPEF), de abrangência nacional contando com cerca de 60 polos em todas as regiões brasileiras, todos com suas primeiras turmas de ingressantes em 2013, entre outras iniciativas em vários lugares do Brasil. Isso permitiu uma disseminação de trabalhos com foco no Ensino básico, com assuntos e metodologias variados, estimulando a produção de pesquisas que resultam em Dissertações e muitas vezes também em comunicações e artigos.

Apesar deste incentivo advindo da criação de novos cursos dedicados à abordagem de Física e Astronomia em sala de aula, os motivos que suportam este cenário de falta de aprofundamento em aspectos relacionados aos itens classificados como E3-E6 são diversos e incluem a falta de disciplinas obrigatórias de Astronomia nas grades curriculares dos cursos de Licenciatura em Física (como evidenciado por uma rápida pesquisa presente na referência da Tabela A6 \#158, p. 3), o que, obviamente, traz bastante insegurança aos professores para a abordagem destes tópicos em sala de aula, apesar do grande interesse dos alunos [9]. Isso é ainda mais evidente no Ensino Fundamental, em que as abordagens relacionadas à Astronomia tipicamente concentram-se em questões mais básicas, como astronomia de posição, as estações do ano e o ciclo da Lua. Além disso, soma-se o fato de que a maior parte dos professores de Ciências do ensino fundamental não são formados em Física e não tem em sua formação treinamento específico para a abordagem da temática estelar [10] e dependem do conteúdo presente nos livros didáticos, que abordam apenas o básico e, muitas vezes, com qualidade questionável [11. No entanto, é notório que estes são tópicos que, apesar de importantes, não atraem tanto a atenção dos alunos em comparação com aqueles associados a temáticas avançadas, como exposto por Gomes Varella (Tabela A1 \#103). Ainda que este cenário mude com os docentes que ministram a disciplina de Física no Ensino Médio, dados do censo escolar realizado em 2019 [12] apontam que mais da metade dos professores $(52,1 \%)$ responsáveis por ministrar a disciplina aos jovens não são bacharéis ou licenciados em Física.

\section{Considerações Finais}

Ao apreciar o panorama na sua generalidade poderíamos afirmar que a "demanda" contemporânea no tema está muito desfasada da "oferta" educacional existente, o que nem é tão estranho dado que a maior parte dos conteúdos astronômicos foram introduzidos nos currículos escolares há quase 1 século, quando toda a Astrofísica atual estava nos primórdios ou nem existia. Os alunos, por sua vez, são hoje expostos a um mundo de informação e fenômenos espetaculares, e resulta natural que isto os estimule a compreender mais a respeito, enquanto a escola se mantém muito alheia, apesar das atualizações que também não resolvem o enorme problema da formação do professor antes mencionado. No Estado de São Paulo apenas após a implantação da proposta Curricular em 2008 é que o Ensino de Astronomia passou efetivamente a fazer parte do Currículo do Ensino Médio dentro do tema: Universo, Terra e Vida, causando de passagem uma disparidade entre o que era ensinado nas licenciaturas e o que é solicitado desde então. 
Anteriormente isto dependia apenas da iniciativa do professor e/ou do livro didático adotado. É importante que a ilustração científica interaja com a nova cultura do aluno, aproximando, assim, a pesquisa da sala de aula. A ligação da ciência com o cotidiano dos alunos, atribui sentido para esse conhecimento, fortalecendo a construção de novas experiências. Sendo assim, o ponto de partida para enriquecer a temática, é propor pesquisas a longo prazo apoiadas por uma didática empírica firmada para o ensino de todas as Ciências. As reformas curriculares em nosso país mostram que a evolução pedagógica é difícil, pois falta conhecimento didático necessário. Mesmo o assunto estando disponível nos currículos, parâmetros e bases nacionais, o ensino de Astronomia ocorre por ciclos, dificultando assim qualquer aproximação pedagógica. Seguindo essa linha, é possível afirmar que é proposto o ensino de Astronomia para os ensinos Fundamental e Médio, porém não se aprofundam nestes assuntos. Falta material necessário, preparo docente e uma articulação mais eficiente no tempo e na metodologia, para que o professor possa utilizar na construção da aprendizagem de forma conceitual, para que, ao final, os alunos consigam descrever um relato detalhado da natureza e a evolução das estrelas. Aproximar a ciência do cotidiano dos alunos permite a interação com uma nova perspectiva. As vivências escolares através das práticas investigativas, proporcionam inovação e desenvolvem argumentação e raciocínio crítico. Os estudos nesta modalidade enriquecem e propiciam conhecimento, tanto para o professor quanto para aos alunos.

A abordagem em sala de aula da Astronomia e Astrofísica Estelar passa de forma concreta pela construção e avaliação de Sequências Didáticas, temas de interesse da área do Ensino de Ciências há bastante tempo 13. Vista como unidade, a Sequência Didática (SD) é uma importante ferramenta de ensino. Embora historicamente (tanto no cenário nacional e internacional) as SDs tenham sido utilizadas como instrumentos de planejamento do ensino, são também objetos de pesquisa em si próprios, e têm como objetivo criar condições favoráveis para os alunos se apropriarem de ferramentas culturais próprias da comunidade científica, ou seja, dos praticantes da disciplina [14]. Assim, a SD auxilia na compreensão da ciência de referência e da sua apresentação no nível escolar [15]. Estes instrumentos de planejamento podem auxiliar nas "atividades ordenadas, estruturadas e articuladas para a realização de certos objetos educacionais, que têm um princípio conhecido tanto pelo professor como pelos alunos" (Ref. [16], p. 18), fundamentando e direcionando a SD. A questão da didática [17] também deve ser ponderada com cuidado, afinal, não é por acaso que os problemas recorrentes na compreensão do sistema Sol-Terra-Lua e outros similares assombram a escola há muito tempo. A assimilação e integração de conteúdos, no caso das estrelas, lúdicos, complexos e interdisciplinares ao mesmo tempo, pode ser estudado por seu interesse intrínseco. Cabe a nós decidirmos, no contexto particular de cada um, como fazer para que o aluno "integre" coisas que a priori nada tem a ver na sua cabeça. Quais SDs construir e aplicar, e baseadas em quê, com o intuito de aproveitar as janelas abertas para estes temas?

Diferentes linhas de pesquisas foram realizadas no ensino-aprendizagem de conteúdos científicos específicos no ensino de Astrofísica como discutido, por exemplo, por Lijnse [18. Estas análises têm o propósito de desenhar uma SD e refletir a respeito de como tal conhecimento é utilizado para a sua construção (com a ideia dos chamados grãos finos) que ocorre de forma coerente, proporcionando a pesquisa cumulativa, maximizando a aprendizagem e estabelecendo a comunicação de forma mais explícita. Embora somente apontemos aqui uma visão muito geral, ao desenvolver uma SD, é de extrema importância o planejamento dessas abordagens comunicativas e de como serão usadas, do que o professor deve estar ciente e da motivação dos alunos nos assuntos que serão ensinados. Aqui temos de novo o problema da formação do professor, que vai muito além da falta de conhecimento dos conteúdos específicos. Para Leach, Ametller e Scott [19], por exemplo, o professor exerce um papel fundamental na introdução de ideias científicas, utilizando a aprendizagem específica, diferenciando o modo de pensamento cotidiano e científico. Nota-se o contraste com as abordagens construtivistas mais radicais.

Para alcançar uma aprendizagem significativa é preciso reflexão ao construir uma SD que deve ocorrer de forma bastante minuciosa, para que as possíveis abordagens ocorram através de uma perspectiva desenvolvida em que seja possível descrever o uso da fala/discurso durante a sequência de ensino. A SD deve ser interpretada de maneira ampla, planejando quais abordagens comunicativas serão usadas, incluindo conversas professor-aluno, gestos e discussões entre colegas (vide por exemplo [20]). Muitas vezes estas observações parecem irrealizáveis na escola pública, sujeita a urgências temporais e com um contexto desfavorável à experimentação. Porém, a introdução de um tema como o das estrelas necessariamente deve passar por estes estágios de elaboração reflexiva a risco de serem inócuos ou até prejudiciais para a formação e cognição do aluno. Salientamos uma possibilidade de se aplicar as SDs ou mesmo abordagens de estrelas como projeto integrador no novo Ensino Médio, produzindo a articulação apresentada entre áreas do conhecimento e em consonância com a BNCC.

Por fim, reconhecemos que o problema da introdução de temas de Astronomia e Astrofísica contemporâneas é uma preocupação de longa data no campo internacional. Somente como exemplo, em Fraknoi 21] a Astronomia é caracterizada como interdisciplinar, porque interage com praticamente todas as disciplinas. Segundo este autor, ela está presente nas Ciências Naturais, nas Ciências 
Sociais, nas Artes, na Música e na Literatura. Na estrutura curricular das escolas de Ensino Fundamental e Médio do Brasil, a Astronomia pode estar presente na Língua Portuguesa, na Química, Física, Biologia, Matemática, Psicologia, Meio Ambiente, Arqueologia, Geologia, Mídia e Sociologia. Na prática, e na realidade brasileira, estes aspectos são os menos abordados, e as estrelas ficam "ligadas" às Ciências, com uma visão mais quantitativa, e rara vez à Cultura e Humanidades em geral. Isto é um paradoxo, pois a BNCC tem um claro eixo na formação integral e abrangente do cidadão, mas não parece que esta oportunidade interdisciplinar seja devidamente aproveitada para estes fins.

Finalmente gostaríamos de apontar que, embora seja um tópico integrador e promissor para a formação dos alunos, existe uma controvérsia entre educadores a respeito da conveniência e as dificuldades de colocar aos estudantes os tópicos do século 21. Pasachoff 22 argumentou com força em favor desta exposição, e obviamente iniciativas como as apresentadas por Fraknoi 21 e outras vão nessa direção "progressista", mas há opiniões contrárias que descreem desta possibilidade, e essas respostas negativas devem ser ponderadas. Recomendamos a leitura do contraponto das Refs. 22] e [23. 24 por completeza e relevância para nossa discussão.

\section{Apêndice A. Relação completa do material coletado ordenado por categorias}

Tabela A1: Artigos da Categoria E1.

\begin{tabular}{|c|c|c|}
\hline Obra & Cat.-Foco & N.Educ. \\
\hline $\begin{array}{l}\text { 1. Uma proposta para o ensino } \\
\text { da Astronomia e Astrofísica } \\
\text { estelares no Ensino Médio. } \\
\text { J.E. Horvath, RBEF } 35 \text {, no.4, } \\
1 \text { (2013) }\end{array}$ & $\begin{array}{l}\text { E1, E2, } \\
\text { E3/ D1, } \\
\text { D3 }\end{array}$ & EM \\
\hline $\begin{array}{l}\text { 2. O Diagrama HR como } \\
\text { ideia-âncora para a } \\
\text { organização prévia no Ensino } \\
\text { de Astronomia e Física. F. } \\
\text { Duarte Calado e H. Luz } \\
\text { Oliveira. Atas do XXI SNEF } \\
\text { (Uberlândia, 2015) }\end{array}$ & $\begin{array}{l}\text { E1, E2, } \\
\text { E3/ D1, } \\
\text { D2 }\end{array}$ & EM \\
\hline $\begin{array}{l}\text { 3. Uma nova abordagem de } \\
\text { conceitos de Física e } \\
\text { Astronomia a partir do } \\
\text { diagrama HR. A.A. Pereira } \\
\text { Beloni. (Dissertação. } \\
\text { Universidade Federal de Mato } \\
\text { Grosso. 2016) }\end{array}$ & $\begin{array}{l}\text { E1, E2, } \\
\text { E3/ D1, } \\
\text { D3, D4 }\end{array}$ & EM \\
\hline $\begin{array}{l}\text { 4. Formação do professor de } \\
\text { Física para o Ensino de } \\
\text { Astronomia: algumas } \\
\text { possibilidades e reflexões. D.E. } \\
\text { Peixoto e E.M. de França } \\
\text { Ramos. Atas do I SNEA (Rio } \\
\text { de Janeiro, 2011) }\end{array}$ & $\begin{array}{l}\text { E1, E4/ } \\
\text { D2 }\end{array}$ & ES \\
\hline
\end{tabular}

\begin{tabular}{|c|c|c|}
\hline $\begin{array}{l}\text { 5. Instrumentos astronômicos } \\
\text { nos trabalhos sobre Educação } \\
\text { apresentados nas Reuniões } \\
\text { Anuais da SAB. G. Brito } \\
\text { Ortelan e P.S. Bretones. Atas } \\
\text { do I SNEA (Rio de Janeiro, } \\
\text { 2011) }\end{array}$ & E1/ D4 & ES \\
\hline $\begin{array}{l}\text { 6. Relatos da disciplina } \\
\text { "Introdução à Astronomia e } \\
\text { Astrofísica" do curso de } \\
\text { Física-Licenciatura à } \\
\text { Distância- da UNIFEI-MG.T. } \\
\text { C. Caetano e G. Hickel. Atas } \\
\text { do I SNEA (Rio de Janeiro, } \\
\text { 2011) }\end{array}$ & $\begin{array}{l}\text { E1-E6/ } \\
\text { D5 }\end{array}$ & $\mathrm{ES}$ \\
\hline $\begin{array}{l}\text { 7. A contagem de estrelas } \\
\text { como tema transversal em } \\
\text { Astronomia. L. Vertchenko e } \\
\text { T. de Aquino Silveira. Atas do } \\
\text { I SNEA (Rio de Janeiro, 2011) }\end{array}$ & $\begin{array}{l}\text { E1/ D1/ } \\
\text { EM }\end{array}$ & EM \\
\hline $\begin{array}{l}\text { 8. Observação visual de Eta } \\
\text { Aquilae: uma atividade } \\
\text { multidisciplinar. A. Amorim. } \\
\text { Atas do I SNEA (Rio de } \\
\text { Janeiro, 2011) }\end{array}$ & $\mathrm{E} 1 / \mathrm{D} 4$ & $\mathrm{EM}, \mathrm{ES}$ \\
\hline $\begin{array}{l}\text { 9. Astronomia e Física } \\
\text { moderna: duas necessidades, } \\
\text { uma solução. G. F. } \\
\text { Marranghello e D. B. Pavani. } \\
\text { Atas do I SNEA (Rio de } \\
\text { Janeiro, 2011) }\end{array}$ & $\begin{array}{l}\text { E1, E2, } \\
\text { E3/ D1, } \\
\text { D3, D4 }\end{array}$ & EM \\
\hline $\begin{array}{l}\text { 10. Uma aplicação da } \\
\text { pedagogia histórico-crítica para } \\
\text { o Ensino Fundamental I com o } \\
\text { tema "Estrelas". M. Lopes } \\
\text { Pinheiro, V. Queiroz e Daniel } \\
\text { Trevisan Sanzovo. Atas do II } \\
\text { SNEA (São Paulo, 2012) }\end{array}$ & $\begin{array}{l}\text { E1, E4/ } \\
\mathrm{D} 1, \mathrm{D} 2\end{array}$ & $\mathrm{EF}$ \\
\hline $\begin{array}{l}\text { 11. Concepções espontâneas } \\
\text { sobre planetas e estrelas: um } \\
\text { estudo nos diferentes niveis de } \\
\text { ensino. V. Pereira de Barros, } \\
\text { A. Braga Oliveira, M. } \\
\text { Bragagnolo e A.L. D. Moreau. } \\
\text { Atas do II SNEA (São Paulo, } \\
\text { 2012) }\end{array}$ & $\begin{array}{l}\text { E1-E4/ } \\
\text { D5/ }\end{array}$ & EM, ES \\
\hline $\begin{array}{l}\text { 12. A observação noturna, } \\
\text { uma metodologia não-formal } \\
\text { para o Ensino da Física. F. R. } \\
\text { O. Silva, Fabricia F. Gonzaga } \\
\text { e Francisco C. R. Fernandes. } \\
\text { Atas do II SNEA (São Paulo, } \\
\text { 2012) }\end{array}$ & E1/ D4 & $\begin{array}{l}\text { EM, } \\
\text { ENF }\end{array}$ \\
\hline $\begin{array}{l}\text { 13. Leitura de imagem da obra } \\
\text { "As Plêiades" de Elihu Vedder: } \\
\text { relações interdisciplinares } \\
\text { entre Artes visuais e } \\
\text { Astronomia. L.L. Ducheiko, } \\
\text { J.A. Parrilha da Silva e M.C. } \\
\text { Danhoni Neves. Atas do III } \\
\text { SNEA (Curitiba, 2014) }\end{array}$ & $\begin{array}{l}\text { E1, E4/ } \\
\mathrm{D} 4, \mathrm{D} 6\end{array}$ & $\mathrm{ES}, \mathrm{ENF}$ \\
\hline
\end{tabular}


Tabela A1: Continued

\begin{tabular}{|c|c|c|}
\hline Obra & Cat.-Foco & N.Educ. \\
\hline $\begin{array}{l}\text { 14. Avaliação de uma Sequência } \\
\text { Didática sobre nossa posição no } \\
\text { Universo aplicada a alunos do } \\
\text { Ensino Médio. T. Pereira da } \\
\text { Silva e S. Mascarello Bisch. Atas } \\
\text { do III SNEA (Curitiba, 2014) }\end{array}$ & $\begin{array}{l}\text { E1/ D4, } \\
\text { D6 }\end{array}$ & EM \\
\hline $\begin{array}{l}\text { 15. Desvendando as estrelas: um } \\
\text { jogo colaborativo para o Ensino } \\
\text { Médio. A. Queiroz Agostinelli } \\
\text { Ribeiro. (Dissertação. } \\
\text { Universidade Federal do ABC. } \\
\text { 2018) }\end{array}$ & $\begin{array}{l}\text { E1, E2, } \\
\text { E3, E5, } \\
\text { E6/ D3 }\end{array}$ & EM \\
\hline $\begin{array}{l}\text { 16. A observação do céu: da } \\
\text { História para entender o Ensino } \\
\text { dentro da Teoria } \\
\text { Histórico-Cultural. T.F. Genzini } \\
\text { de Carvalho e J. Lopes de } \\
\text { Almeida Pacca. Atas do III } \\
\text { SNEA (Curitiba, 2014) }\end{array}$ & $\begin{array}{l}\text { E1, E4/ } \\
\text { D6 }\end{array}$ & EM \\
\hline $\begin{array}{l}\text { 17. Um modelo com } \\
\text { representação tridimensional do } \\
\text { Cruzeiro do Sul como atividade } \\
\text { para o Ensino de Astronomia. } \\
\text { D.S. Garcia e H.P.S. Corrêa. Atas } \\
\text { do III SNEA (Curitiba, 2014) }\end{array}$ & E1/ D4 & EM \\
\hline $\begin{array}{l}\text { 18. Luz em } 7 \text { tons: } \\
\text { Desenvolvimento de atividades } \\
\text { com a temática luz para a } \\
\text { educação infantil. E. Bezerra de } \\
\text { Lima. (Dissertação. Instituto } \\
\text { Federal de Educação, Ciência e } \\
\text { Tecnologia do Rio Grande do } \\
\text { Norte. 2018) }\end{array}$ & $\begin{array}{l}\text { E1/ D1, } \\
\text { D4 }\end{array}$ & $\mathrm{EF}$ \\
\hline $\begin{array}{l}\text { 19. Potencialidades do Ensino de } \\
\text { Astronomia para uma formação } \\
\text { pautada na diversidade cultural: } \\
\text { os céus dos povos indígenas no } \\
\text { Brasil. M. de Souza Rodrigues e } \\
\text { C. Leite. Atas do III SNEA } \\
\text { (Curitiba, 2014) }\end{array}$ & $\begin{array}{l}\mathrm{E} 1, \mathrm{E} 4 / \\
\mathrm{D} 1, \mathrm{D} 2\end{array}$ & $\begin{array}{l}\text { EF, } \\
\text { EM }\end{array}$ \\
\hline $\begin{array}{l}\text { 20. Ensino de Física por meio de } \\
\text { atividades de Ensino } \\
\text { Investigativo e experimentais de } \\
\text { Astronomia no Ensino Médio. R. } \\
\text { Assenso (Dissertação. } \\
\text { Universidade Federal do ABC. } \\
\text { 2017) }\end{array}$ & $\begin{array}{l}\text { E1, E2, } \\
\text { E3/ D1, } \\
\text { D3, D4 }\end{array}$ & EM \\
\hline $\begin{array}{l}\text { 21. Representações sobre as } \\
\text { estruturas do Universo em uma } \\
\text { visita ao planetário: um estudo } \\
\text { exploratório. B.R. Gomes dos } \\
\text { Santos e A.S. de Medeiros } \\
\text { Germano. Atas do IV SNEA } \\
\text { (Goiânia, 2016) }\end{array}$ & E1/ D4 & ENF \\
\hline $\begin{array}{l}\text { 22. Modelos mentais sobre } \\
\text { estrelas elaborados por estudantes } \\
\text { do } 7 \text { mo ano do Ensino } \\
\text { Fundamental a partir da } \\
\text { literatura infantil. E. Freitas } \\
\text { Moraes Borges, P.H. de Azevedo } \\
\text { Sobreira e J. P.Machado Ribeiro. } \\
\text { Atas do V SNEA (Londrina, } \\
\text { 2018) }\end{array}$ & $\begin{array}{l}\text { E1, E2, } \\
\text { E3/ D3, } \\
\text { D5 }\end{array}$ & $\mathrm{EF}$ \\
\hline
\end{tabular}

23. As constelações e seus mitos: o que sonham as crianças quando olham para o céu estrelado? A.R. Barreda e R.K. Kimura. Atas do V SNEA (Londrina, 2018) 24. O uso do software Stellarium no Ensino de Astronomia: um estudo teórico. M. Hilgert

Pacheco, Jr. de Lima, M.

Schmitt Zanella. Atas do V SNEA (Londrina, 2018) 25. Baixando estrelas: uma proposta de aplicativo móvel acessível para Ensino de Astronomia a pessoas com deficiência visual. A.C. S.

Frizzera, D. V. C. Sondermann, A. Caetano, V. R. Passose, G. B. K. Lopes. Atas do V SNEA (Londrina, 2018)

\section{Análise de espectros}

utilizando um espectroscópio caseiro. M.A. Amorim, D. Alves de Farias, E.M. dos Anjos, E.C. Viana Nascimento e W.F. da Silva. Atas do V SNEA (Londrina, 2018)

27. Proposta experimental para a determinação da cintilação das estrelas. C.M. Sitko, A. Alves Mesquita e R. de Almeida. Atas do V SNEA (Londrina, 2018)

28. Uma proposta de observação do céu. T. Permino Rogério e S. Mascarello Bisch. Atas do V SNEA (Londrina, 2018) 29. Astrofísica escolar: brincando com dados observacionais. H.D.

Navone, M. Scancich e

R.A.Vázquez. RELEA 11, 81 (2011)

30. O conhecimento prévio de alunos do Ensino Médio sobre as estrelas. G. Iachel. RELEA 12, 7 (2011)

31. Simulando medidas de distâncias a estrelas em laboratório. R. dos Santos Menezes Jr., N.O.L. de Oliveira e C.L. Pereira. RELEA 24, 7 (2017)

32. Os múltiplos sóis: a

Arte-Ciência da Astronomia e da

Ficção Científica na difusão da

Ciência. R.K. Kimura e L.P.

Piassi. RELEA 25, 7 (2018)

33. Estrelas variáveis no contexto

educacional: uma proposta

envolvendo a observação de cefeidas clássicas no Ensino

Médio. D.I. Machado. RELEA 28, 7 (2019)

\begin{tabular}{|l|l|}
\hline $\begin{array}{l}\text { E1, E4/ } \\
\text { D3, D5 }\end{array}$ & $\begin{array}{l}\text { EF } \\
\text { ENF }\end{array}$ \\
$\begin{array}{l}\text { E1/ D3, } \\
\text { D4 }\end{array}$ & $\begin{array}{l}\text { EM, } \\
\text { ES }\end{array}$ \\
\hline E1/ D4 & $\begin{array}{l}\text { EF, } \\
\text { EM } \\
\text { ES }\end{array}$ \\
\hline
\end{tabular}

E1,

D4
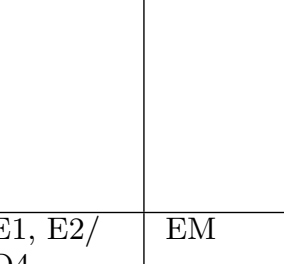

\begin{tabular}{|l|l|l|} 
& $\mathrm{E} 1 / \mathrm{D} 4$ & $\mathrm{EM}$ \\
& \\
\hline
\end{tabular}

1/ D3, EF,

D4 EM,

$\mathrm{ENF}$

E1, E2/ $\quad$ EM

D1, D3,

D4

\begin{tabular}{|l|l}
\hline $\mathrm{E} 1-\mathrm{E} 6 /$ & $\mathrm{EM}$ \\
$\mathrm{D} 5$ &
\end{tabular}

\begin{tabular}{l|l} 
E1/ D4 & EM \\
& ES
\end{tabular}

$\mathrm{ES}$

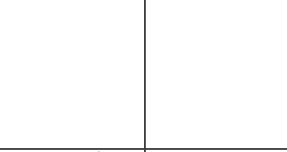

\begin{tabular}{l|l} 
D3, E4/ & EM, \\
ENF
\end{tabular}

E1, E2, $\quad$ EM

E3/ D4

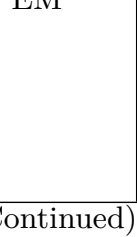


Tabela A1: Continued

\begin{tabular}{|c|c|c|}
\hline Obra & Cat.-Foco & N.Educ. \\
\hline $\begin{array}{l}\text { 34. Uma prática observacional } \\
\text { em Astrofísica: o diagrama HR } \\
\text { de aglomerados abertos. R. } \\
\text { Kalbusch Saito e R. Baptista } \\
\text { CBEF } 18,182(2001)\end{array}$ & $\begin{array}{l}\text { E1, E2, } \\
\text { E3/ D3, } \\
\text { D4 }\end{array}$ & $\begin{array}{l}\text { EM, } \\
\text { ES }\end{array}$ \\
\hline $\begin{array}{l}\text { 35. O ensino de Astronomia: } \\
\text { recriando uma esfera celeste } \\
\text { didática. A.G. Trogello, M.C. } \\
\text { Danhoni Neves e S. de Carvalho } \\
\text { Rutz da Silva CBEF } 32,223 \\
(2015)\end{array}$ & E1/ D4 & $\begin{array}{l}\text { EF, } \\
\text { EM }\end{array}$ \\
\hline $\begin{array}{l}\text { 36. Objeto virtual de } \\
\text { aprendizagem no ensino de } \\
\text { Astronomia: Algumas situações } \\
\text { problemas propostas a partir do } \\
\text { software Stellarium. M.D. } \\
\text { Longhini e M.D. de Deus } \\
\text { Menezes CBEF 27, } 433 \text { (2010) } \\
\text { E1/ D3, D4/ EM, ES, ENF }\end{array}$ & $\begin{array}{l}\text { E1/ D3, } \\
\text { D4 }\end{array}$ & $\begin{array}{l}\text { EM, } \\
\text { ES, } \\
\text { ENF }\end{array}$ \\
\hline $\begin{array}{l}\text { 37. Como queimar um papel à luz } \\
\text { de Sírio. G. de Almeida. CBEF } \\
\text { 30, } 440 \text { (2013) }\end{array}$ & $\mathrm{E} 1 / \mathrm{D} 4$ & $\begin{array}{l}\text { EM, } \\
\text { ES }\end{array}$ \\
\hline $\begin{array}{l}\text { 38. Um problema didático: como } \\
\text { determinar ângulos de paralaxe } \\
\text { trigonométrica. F. Catelli, } \\
\text { O. Giovannini e P. Hoffmann, } \\
\text { RBEF 40, (2018) }\end{array}$ & E1/ D3 & EM \\
\hline $\begin{array}{l}\text { 39. A construção de um antigo } \\
\text { instrumento para navegação } \\
\text { marítima e seu emprego em aulas } \\
\text { de Astronomia e Matemática. } \\
\text { T.C. Dias Fernandes e M.D. } \\
\text { Longhini. Atas do I SNEA (Rio } \\
\text { de Janeiro, 2011) }\end{array}$ & E1/ D4 & EM \\
\hline $\begin{array}{l}\text { 40. Aprendendo física com as } \\
\text { estrelas binárias. D.R.C. Mello, } \\
\text { RBEF } 36,1 \text { (2014) }\end{array}$ & E1/ D1 & EM \\
\hline $\begin{array}{l}\text { 41. Fotografando estrelas com } \\
\text { uma câmera digital. P.A. } \\
\text { Ourique, O. Giovannini e F. } \\
\text { Catelli, F. RBEF32, } 1302 \text { (2010) }\end{array}$ & E1/ D1 & $\begin{array}{l}\text { EF, } \\
\text { EM }\end{array}$ \\
\hline $\begin{array}{l}\text { 42. Estudo da atividade estelar } \\
\text { da Kepler-289 a partir da } \\
\text { modelagem de trânsitos } \\
\text { planetários. A.A. de Souza e } \\
\text { A.R. Valio, RBEF } 41,(2019) \\
\end{array}$ & $\begin{array}{l}\text { E1, E2, } \\
\text { E3/ D1 }\end{array}$ & $\mathrm{ES}$ \\
\hline $\begin{array}{l}\text { 43. A rotação estelar e seu efeito } \\
\text { sobre os espectros. R.S. } \\
\text { Levenhagen e R. Künzel, RBEF } \\
30,4701 \text { (2008) }\end{array}$ & $\begin{array}{l}\text { E1, E2/ } \\
\text { D1 }\end{array}$ & $\mathrm{ES}$ \\
\hline $\begin{array}{l}\text { 44. Transformação de } \\
\text { coordenadas aplicada à } \\
\text { construção da maquete } \\
\text { tridimensional de uma } \\
\text { constelação. G.M. dos Santos } \\
\text { Silva, F.B. Ribas e M.S.T. de } \\
\text { Freitas, RBEF 30, } 1306 \text { (2008) }\end{array}$ & E1/ D1 & $\begin{array}{l}\text { EM, } \\
\text { ES }\end{array}$ \\
\hline $\begin{array}{l}\text { 45. Atividades de observação e } \\
\text { identificação do céu adaptadas às } \\
\text { pessoas com deficiência visual. } \\
\text { T.P. Dominici et al. RBEF } 30 \text {, } \\
4501 \text { (2008) }\end{array}$ & E1/ D1 & $\begin{array}{l}\text { EF, } \\
\text { EM, } \\
\text { ENF }\end{array}$ \\
\hline
\end{tabular}

\begin{tabular}{|c|c|c|}
\hline $\begin{array}{l}\text { 46. Polarización de la luz: } \\
\text { conceptos básicos y aplicaciones } \\
\text { en astrofísica. J.M. Rodríguez, } \\
\text { RBEF 40, (2018) }\end{array}$ & $\begin{array}{l}\text { E1, E6/ } \\
\text { D1 }\end{array}$ & ES \\
\hline $\begin{array}{l}\text { 47. Descobertas de exoplanetas } \\
\text { pelo método do trânsito. W.C. } \\
\text { Santos e R.G.G. Amorim, RBEF } \\
\text { 39, (2017) }\end{array}$ & E1/ D1 & $\mathrm{ES}$ \\
\hline $\begin{array}{l}\text { 48. Eclipses: revelando a vida } \\
\text { secreta das estrelas e da natureza } \\
\text { humana. D.B. de Freitas, RBEF } \\
\text { 41, (2019) }\end{array}$ & $\begin{array}{l}\text { E1, E4/ } \\
\text { D1, D6 }\end{array}$ & $\begin{array}{l}\text { EM, } \\
\text { ES }\end{array}$ \\
\hline $\begin{array}{l}\text { 49. Astronomia nos livros } \\
\text { didáticos de Ciências - um } \\
\text { panorama atual. C. Leite e Y. } \\
\text { Hosoume. Atas do XVI SNEF } \\
\text { (Rio de Janeiro, 2005) }\end{array}$ & $\begin{array}{l}\text { E1, E4/ } \\
\text { D4 }\end{array}$ & $\mathrm{EF}$ \\
\hline $\begin{array}{l}\text { 50. Articulação Entre Espaços } \\
\text { Formais E Não Formais De } \\
\text { Aprendizagem Visando O Ensino } \\
\text { De Conceitos De Astronomia. } \\
\text { D.C. Nardo Elias e M.S.T. } \\
\text { Araújo. Atas do XVII SNEF } \\
\text { (São Luis, 2007) }\end{array}$ & $\begin{array}{l}\text { E1, E2/ } \\
\text { D1, D2 }\end{array}$ & $\begin{array}{l}\text { EM, } \\
\text { ENF }\end{array}$ \\
\hline $\begin{array}{l}\text { 51. A evoluçâao dos instrumentos } \\
\text { de observaçâo astronômica e o } \\
\text { contexto histórico-científico. } \\
\text { V.C.Alves, M.S.V. Quintilio, E.P. } \\
\text { Perez e A.C. Força. Atas do } \\
\text { XVII SNEF (São Luis, 2007) }\end{array}$ & $\begin{array}{l}\text { E1/ D1, } \\
\text { D3, D6 }\end{array}$ & EM \\
\hline $\begin{array}{l}\text { 52. A utilização da História da } \\
\text { Ciência no ensino de Física: } \\
\text { investigando o contexto da } \\
\text { construção do espectroscópio de } \\
\text { chamas. M.A. Monteiro e R.A. } \\
\text { Nardi. Atas do XVII SNEF. (São } \\
\text { Luis, 2007) }\end{array}$ & $\begin{array}{l}\text { E1/ D1, } \\
\text { D2, D6 }\end{array}$ & $\begin{array}{l}\text { EM, } \\
\text { ES }\end{array}$ \\
\hline $\begin{array}{l}\text { 53. Levantamento das concepções } \\
\text { de professoras das séries iniciais } \\
\text { do Ensino Fundamental sobre } \\
\text { alguns tópicos de Astronomia e } \\
\text { suas implicações para a } \\
\text { Formação Continuada. L. Bolina } \\
\text { Costa e D. Coimbra. Atas do } \\
\text { XVIII SNEF (Vitória, 2009) }\end{array}$ & E1/ D2 & $\mathrm{EF}$ \\
\hline $\begin{array}{l}\text { 54. Introdução à astronomia e a } \\
\text { astrofísica?: relatos de um curso } \\
\text { a distância. T.C. Caetano e W.S. } \\
\text { Dias. Atas do XVIII SNEF } \\
\text { (Vitória, 2009) }\end{array}$ & $\begin{array}{l}\text { E1, E2, } \\
\text { E3/ D2, } \\
\text { D6 }\end{array}$ & $\mathrm{ES}$ \\
\hline $\begin{array}{l}\text { 55. Formação continuada de } \\
\text { professores para o ensino de } \\
\text { astronomia. G. Iachel, R.M.F. } \\
\text { Scalvi e R. Nardi. Atas do XVIII } \\
\text { SNEF (Vitória, 2009) }\end{array}$ & $\begin{array}{l}\text { E1, E2, } \\
\text { E3/ D2 }\end{array}$ & EM \\
\hline $\begin{array}{l}\text { 56. Curso de Extensão } \\
\text { Universitária - Astronomia?: } \\
\text { Uma nova visão da Física no } \\
\text { Ensino. A.T. Mota, R. Meloni, } \\
\text { M. Rosado e N.Figueiredo. Atas } \\
\text { do XVIII SNEF (Vitória, 2009) }\end{array}$ & $\begin{array}{l}\text { E1, E2, } \\
\text { E3/ D1, } \\
\text { D2 }\end{array}$ & $\mathrm{ES}$ \\
\hline
\end{tabular}


Tabela A1: Continued

\begin{tabular}{|c|c|c|}
\hline Obra & Cat.-Foco & N.Educ. \\
\hline $\begin{array}{l}\text { 57. Sequência de aulas de } \\
\text { Astronomia: da Espectroscopia à } \\
\text { Cosmologia. K.N. Skolimoski, } \\
\text { J.N. Teixeira e M.P. Allen. Atas } \\
\text { do XIX SNEF (Manaus, 2011) }\end{array}$ & $\begin{array}{l}\mathrm{E} 1, \mathrm{E} 2 / \\
\mathrm{D} 3, \mathrm{D} 4\end{array}$ & EM \\
\hline $\begin{array}{l}\text { 58. A implementação de um } \\
\text { Centro de Astronomia?: } \\
\text { Caracterizando os obstáculos } \\
\text { epistemológicos dos alunos. S.S. } \\
\text { Moraes, J.R. Sabino e L.G.R. } \\
\text { Gonzaga. Atas do XIX SNEF } \\
\text { (Manaus, 2011) }\end{array}$ & $\begin{array}{l}\text { E1, E2, } \\
\text { E3/ D3, } \\
\text { D5 }\end{array}$ & $\mathrm{EF}$ \\
\hline $\begin{array}{l}\text { 59. Construção de uma luneta } \\
\text { com materiais de baixo custo?: } \\
\text { Uma aula experimental em } \\
\text { Astronomia realizado pelo PIBID } \\
\text { em Natal-RN. R.M.S. de Moura, } \\
\text { M. R. da Silva, A.M. Bezerra, } \\
\text { J.B. de Araújo e P.C. da Silva } \\
\text { Filho. Atas do XIX SNEF } \\
\text { (Manaus, 2011) }\end{array}$ & $\begin{array}{l}\text { E1/ D1, } \\
\text { D2 }\end{array}$ & EM \\
\hline $\begin{array}{l}\text { 60. Desenvolvimento de um } \\
\text { material paradidático visando } \\
\text { atrelar o Ensino de Física à } \\
\text { Astronomia sob um ponto de } \\
\text { vista diferente do proposto pelas } \\
\text { PCN+. R.M.M. Rosado. Atas do } \\
\text { XIX SNEF (Manaus, 2011) }\end{array}$ & $\begin{array}{l}\text { E1, E3, } \\
\text { E6/ D4 }\end{array}$ & EM \\
\hline $\begin{array}{l}\text { 61. O Ensino De Astronomia em } \\
\text { uma Escola Básica a partir de } \\
\text { uma Pesquisa Colaborativa entre } \\
\text { Universidade-Escola no âmbito } \\
\text { do projeto PIBID/CAPES. } \\
\text { M.A.M. Delgado, A.L. de Mello } \\
\text { Ferreira, G. Pereira Moraes e G. } \\
\text { S. M. de Lima Trinidade. Atas } \\
\text { do XIX SNEF (Manaus, 2011) }\end{array}$ & $\begin{array}{l}\text { E1/ D1, } \\
\text { D2 }\end{array}$ & $\mathrm{EF}$ \\
\hline $\begin{array}{l}\text { 62. Ludoastronomia?: Um Jogo } \\
\text { De Tabuleiro Para O Ensino De } \\
\text { Astronomia. R.F. Pereira, P.A. } \\
\text { Fusinato, M.C. Danhoni e M.C. } \\
\text { Batista. Atas do XIX SNEF } \\
\text { (Manaus, 2011) }\end{array}$ & $\begin{array}{l}\text { E1, E2/ } \\
\text { D4 }\end{array}$ & $\mathrm{EF}$ \\
\hline $\begin{array}{l}\text { 63. Aprendendo a medir a } \\
\text { Radiação Solar com um } \\
\text { Radiometro de baixo custo?: um } \\
\text { Experimento. M. Alves e C. } \\
\text { Mirabel. Atas do XIX SNEF } \\
\text { (Manaus, 2011) }\end{array}$ & E1/ D4 & $\begin{array}{l}\mathrm{EF}, \\
\mathrm{EM}\end{array}$ \\
\hline $\begin{array}{l}\text { 64. O Ensino da Astronomia: } \\
\text { Revivendo o Projeto Céu. A.I.E. } \\
\text { de Monteiro, J.M. de Souza, C.R. } \\
\text { da Silva Dantas e A.F. Gonçalves } \\
\text { Silva. Atas do XIX SNEF } \\
\text { (Manaus, 2011) }\end{array}$ & E1/ D4 & EM \\
\hline $\begin{array}{l}\text { 65. Jornadas Astronômicas para } \\
\text { público infantil. T.P. dos Santos, } \\
\text { E. Bezerra de Lima, A.C. } \\
\text { Mattiuci, E.J. da Silva e } \\
\text { A.Araújo Sobrinho. Atas do XIX } \\
\text { SNEF (Manaus, 2011) }\end{array}$ & E1/D1 & $\begin{array}{l}\text { EF, } \\
\text { ENF }\end{array}$ \\
\hline
\end{tabular}

66. Utilização de Um

Mini-Planetário de baixo custo? a Arte das Projeções Celestes para popularização da Astronomia no Ensino Médio. D. dos Santos Leão, C.C. Laranjeiras e M. Ferreira Coelho. Atas do XIX SNEF (Manaus, 2011)

67. A importância da observação do céu no quotidiano escolar?: o ponto de vista do professor. T.F. Genzini Carvalho e J.L de Almeida Pacca. Atas do XX SNEF (São Paulo, 2013)

68. Instrumentação Para $O$

Ensino De Física Moderna?: Um Kit De Baixo Custo Para

Espectroscopia. C. Tavolaro, M.A. Cavalcante, A de Castro Teixeira e R. Peçanha. Atas do XX SNEF (São Paulo, 2013)

69. Aprendendo Astronomia no IFG - Câmpus Jataí. C. Bueno Silva, M. João e F. Silva. Atas do XX SNEF (São Paulo, 2013)

70. Temas de Astronomia na Escola Básica: investigação de cenários em duas regiões do Rio Grande do Sul. S.E.M. Gonzatti, A.S. Maman, E.F. Borragini, J.C. Kerber e M.H. Steffani. Atas do XX SNEF (São Paulo, 2013)

71. Astronomia como tema estruturante de uma unidade. C.

Alencar de Souza e A. M. Martins Marciel. Atas do XXI SNEF

(Uberlândia, 2015)

72. Oficina Astronômica: Uma proposta de atividades utilizando materiais potencialmente significativos para o Ensino Médio. M.P. Gonçalves e M.H. Steffani. Atas do XXI SNEF (Uberlândia, 2015)

73. Uso da Astronomia e

Matemática para promover a

Divulgação Científica. A. W.T.

Silva, J. Antunes de Macedo e M.

R. Voelzke. Atas do XXI SNEF

(Uberlândia, 2015)

74. História da Astronomia e

Natureza da Ciência em

quadrinhos?: Potencialidades $e$

Possibilidades de articulação com o livro didático. M.M. da Silva, J.M. Hidalgo Ferreira, J.D. dos Santos Nicácio e D.S. Fonseca. Atas do XXI SNEF (Uberlândia, 2015)

75. Uma Abordagem do efeito

Doppler para alunos com

deficiência visual. B. Araújo

Ferreira, M. Binderly Gaspar e

A.C. Azevedo. Atas do XXI SNEF (Uberlândia, 2015)

\begin{tabular}{|c|c|}
\hline E1/ D4 & EM \\
\hline $\begin{array}{l}\text { E1/ D1, } \\
\text { D2 }\end{array}$ & $\begin{array}{l}\text { EF, } \\
\text { EM }\end{array}$ \\
\hline E1/ D4 & EM \\
\hline E1/ D1 & $\begin{array}{l}\text { EF, } \\
\text { EM }\end{array}$ \\
\hline E1/ D2 & $\mathrm{EF}$ \\
\hline $\begin{array}{l}\text { E1, E2, } \\
\text { E3/ D1, } \\
\text { D4 }\end{array}$ & EM \\
\hline $\begin{array}{l}\text { E1/ D1, } \\
\text { D4 }\end{array}$ & EM \\
\hline $\begin{array}{l}\text { E1/ D1, } \\
\text { D4 }\end{array}$ & EM \\
\hline $\begin{array}{l}\text { E1, E4/ } \\
\text { D3, D4, } \\
\text { D6 }\end{array}$ & EM \\
\hline $\begin{array}{l}\text { E1/ D3, } \\
\text { D4 }\end{array}$ & EM \\
\hline
\end{tabular}

(Continued) 
Tabela A1: Continued

\begin{tabular}{|c|c|c|}
\hline Obra & Cat.-Foco & N.Educ. \\
\hline $\begin{array}{l}\text { 76. Uma proposta de exploração } \\
\text { conceitual em situação de } \\
\text { educação não formal: } \\
\text { transcendendo da observação com } \\
\text { um telescópio para a iniciação à } \\
\text { astronomia. T.C. Caetano, J.R. } \\
\text { Neves da Silva, A. Pina da Silva, } \\
\text { I.M.C.A. Menezes, J. da Paula } \\
\text { Neves e J.M. Neto. Atas do XXI } \\
\text { SNEF (Uberlândia, 2015) }\end{array}$ & $\begin{array}{l}\text { E1/ D1, } \\
\text { D3 }\end{array}$ & $\begin{array}{l}\text { EM, } \\
\text { ENF }\end{array}$ \\
\hline $\begin{array}{l}\text { 77. Uma proposta de Sequência } \\
\text { Didática para implantação de um } \\
\text { clube de Astronomia no Ensino } \\
\text { Médio. J. Moura Aguiar } \\
\text { (Dissertação. Universidade } \\
\text { Estadual de Santa Cruz. 2017) }\end{array}$ & $\begin{array}{l}\text { E1, E2, } \\
\text { E3, E5, } \\
\text { E6/ D1, } \\
\text { D4 }\end{array}$ & EM \\
\hline $\begin{array}{l}\text { 78. Análise das concepções } \\
\text { astronômicas de futuros } \\
\text { professores de Ciências da } \\
\text { Natureza e Matemática. J. } \\
\text { Antunes de Macedo e M.R. } \\
\text { Voelzke. Atas do XXI SNEF } \\
\text { (Uberlândia, 2015) }\end{array}$ & $\begin{array}{l}\text { E1/ D2, } \\
\text { D5 }\end{array}$ & $\mathrm{ES}$ \\
\hline $\begin{array}{l}\text { 79. Uma avaliação sobre a } \\
\text { opinião e a motivação dos } \\
\text { estudantes que participaram de } \\
\text { uma sessão de observação do } \\
\text { céu. S.G.S. Silva, S. Bisch e G. } \\
\text { Camiletti. Atas do XXI SNEF. } \\
\text { (Uberlândia, 2015) }\end{array}$ & E1/D1 & EM \\
\hline $\begin{array}{l}\text { 80. Astronomia no estudo da } \\
\text { Física: uma proposta e suas } \\
\text { contribuições para a formação } \\
\text { docente. J.R.F. de Oliveira, E. } \\
\text { dos R. Nunes, R.B. Strieder e } \\
\text { D.A. Soares. Atas do XXI SNEF. } \\
\text { (Uberlândia, 2015) }\end{array}$ & $\begin{array}{l}\text { E1, E2, } \\
\text { E3/ D2 }\end{array}$ & EM \\
\hline $\begin{array}{l}\text { 81. Utilização do material do } \\
\text { NASE em sala de aula. M.S. } \\
\text { Kitagawa. Atas do XXI SNEF } \\
\text { (Uberlândia, 2015) }\end{array}$ & $\begin{array}{l}\text { E1, E3/ } \\
\text { D2 }\end{array}$ & $\begin{array}{l}\text { EF, } \\
\text { EM }\end{array}$ \\
\hline $\begin{array}{l}\text { 82. O Funk e o Rock nas } \\
\text { estrelas?: uma oficina para o } \\
\text { ensino de Astronomia. N.R. de } \\
\text { Barros, F. de Assis Jr. e L.P } \\
\text { Piassi. Atas do XXII SNEF (São } \\
\text { Carlos, 2017) }\end{array}$ & $\begin{array}{l}\text { E1/ D3, } \\
\text { D4 }\end{array}$ & EM \\
\hline $\begin{array}{l}\text { 83. Interesse e motivação no } \\
\text { Ensino de Astronomia. D.E. } \\
\text { Peixoto e U. Kleinke. Atas do } \\
\text { XXII SNEF. (São Carlos, 2017) }\end{array}$ & $\begin{array}{l}\text { E1, E2, } \\
\text { E3/ D5 }\end{array}$ & EM \\
\hline $\begin{array}{l}\text { 84. Astronomia Dogon e } \\
\text { Natureza da Ciência?: Caminhos } \\
\text { para o estudo da História e } \\
\text { Cultura Africana nas Escolas. } \\
\text { A.L. de Moura Pessoa, G.R. } \\
\text { Pessôa Campello Queiroz e J.C. } \\
\text { dos Santos Moreira. Atas do } \\
\text { XXII SNEF (São Carlos, 2017) }\end{array}$ & $\begin{array}{l}\text { E1, E4/ } \\
\text { D2, D3 }\end{array}$ & EM \\
\hline
\end{tabular}

85. Astronomia em Concerto?: as potencialidades e dificuldades de um mini-curso no contra turno de uma escola pública. R. Lopes, P. Assunção, T. Maciel, P. Gontijo e E. Rodrigues. Atas do XXII SNEF (São Carlos, 2017) 86. Abordando conceitos de Fúsica no Ensino Médio através da Astronomia. J. de Paula Neves e M.D. Moreira. Atas do XXII SNEF (São Carlos, 2017)

\section{Astronomia e}

Termodinâmica?: Uma forma alternativa de Ensino. J. Santos, M. Deorce, A. Silva e R. Santos. Atas do XXIII SNEF (Salvador, 2019)

88. Rotação diferencial do Sol.

M.L. Castanheira e D.W. Foryta. Atas do XXIII SNEF (Salvador, 2019)

\section{Explorando a dimensão}

espacial na pesquisa em Ensino de

Astronomia, C. Leite e Y.

Hossume. REEC 8, 797 (2008)

90. Uma proposta metodológica de uma oficina de Astrofísica no

Ensino Médio. B.W. de Freitas

Alves (TCC. Universidade Federal do Ceará. 2019).

91. Cosmologia e Astrofísica no ensino secundário. T.I. Gonçalves do Carmo (Dissertação.

Universidade de Algarve. 2003)

\section{Inclusão de Astrofísica e}

Cosmologia no Ensino Médio:

uma motivação ao estudo de

ciências. E.C. Ferreira (TCC.

Universidade Estadual Paulista.

2011)

93. Uma proposta de ensino de

fundamentos de Astronomia e

Astrofísica via Ensino sob Medida.

T. Nunes Cestari (Dissertação.

Universidade Federal do Rio

Grande do Sul. 2018)

94. $O$ ensino de fundamentos de

Astronomia e Astrofísica na

modalidade a distância para

alunos de graduação. A. Machado

Müller (Dissertação. Universidade

Federal do Rio Grande do Sul.

2013).

95. Da Astronomia a Astrofísica: um curso para Ensino Médio. E.

L. da Cunha (Dissertação.

Universidade Federal de Santa

Catarina. 2017)

\begin{tabular}{|c|c|}
\hline E1, E3/ & $\mathrm{EM}$ \\
\hline $\begin{array}{l}\text { E1, E2, } \\
\text { E3/ D2, } \\
\text { D3 }\end{array}$ & EM \\
\hline $\begin{array}{l}\text { E1, E2, } \\
\text { E3/ D3, } \\
\text { D4 }\end{array}$ & EM \\
\hline $\begin{array}{l}\text { E1, E2/ } \\
\text { D3, D4 }\end{array}$ & $\mathrm{EM}$ \\
\hline $\begin{array}{l}\text { E1, E4/ } \\
\text { D2, D5 }\end{array}$ & ES \\
\hline $\begin{array}{l}\text { E1/ D3, } \\
\text { D4, D5, } \\
\text { D6 }\end{array}$ & EM \\
\hline $\begin{array}{l}\text { E1, E5/ } \\
\text { D1 }\end{array}$ & EM \\
\hline $\begin{array}{l}\text { E1, E2/ } \\
\text { D2, D4 }\end{array}$ & EM \\
\hline $\begin{array}{l}\text { E1, E2, } \\
\text { E3/ D2 }\end{array}$ & EM \\
\hline $\begin{array}{l}\text { E1, E2, } \\
\text { E3/ D2, } \\
\text { D5 }\end{array}$ & ES \\
\hline $\begin{array}{l}\text { E1, E2, } \\
\text { E3/ D1 }\end{array}$ & EM \\
\hline
\end{tabular}


Tabela A1: Continued

\begin{tabular}{|c|c|c|}
\hline Obra & Cat.-Foco & N.Educ. \\
\hline $\begin{array}{l}\text { 96. Astrofísica Estelar para o } \\
\text { Ensino Médio: uma abordagem } \\
\text { empírica baseada na observação } \\
\text { visual das estrelas variáveis. } \\
\text { T.A.J. Napoleão (Dissertação. } \\
\text { Universidade de São Paulo. } \\
\text { 2018.) }\end{array}$ & $\begin{array}{l}\text { E1, E2/ } \\
\text { D3 }\end{array}$ & EM \\
\hline $\begin{array}{l}\text { 97. O nível de conhecimento dos } \\
\text { professores de ensino } \\
\text { fundamental e médio de algumas } \\
\text { escolas públicas do município de } \\
\text { Ariquemes- } R O \text { em relação às } \\
\text { ciências astronômicas. I. } \\
\text { Fernandes Gomes (TCC. } \\
\text { Faculdade de Educação e Meio } \\
\text { Ambiente. 2011). }\end{array}$ & $\begin{array}{l}\text { E1/ D1, } \\
\text { D2 }\end{array}$ & $\begin{array}{l}\text { EF, } \\
\mathrm{EM}\end{array}$ \\
\hline $\begin{array}{l}\text { 98. Ensino de Astronomia na } \\
\text { perspectiva da inclusão de } \\
\text { deficientes visuais em aulas de } \\
\text { Física do Ensino Médio. R. } \\
\text { Gomes Coelho da Rocha } \\
\text { (Dissertação. Universidade } \\
\text { Federal Fluminense. 2016). }\end{array}$ & $\begin{array}{l}\text { E1/ D2, } \\
\text { D3, D5 }\end{array}$ & EM \\
\hline $\begin{array}{l}\text { 99. Disciplinas introdutórias de } \\
\text { Astronomia nos cursos superiores } \\
\text { do Brasil. P.S. Bretones } \\
\text { (Dissertação. Universidade } \\
\text { Estadual de Campinas. 1999). }\end{array}$ & $\begin{array}{l}\mathrm{E} 1, \mathrm{E} 4 / \\
\mathrm{D} 1, \mathrm{D} 5\end{array}$ & $\mathrm{ES}$ \\
\hline $\begin{array}{l}\text { 100. Uma sondagem sobre a } \\
\text { implicação da formação inicial } \\
\text { docente no ensino de } \\
\text { Astronomia. N. Menezes Cunha } \\
\text { (TCC. Instituto Federal de Santa } \\
\text { Catarina. 2018) }\end{array}$ & $\begin{array}{l}\text { E1/ D1, } \\
\text { D5 }\end{array}$ & $\mathrm{ES}$ \\
\hline $\begin{array}{l}\text { 101. Emprego da Astrofotografia } \\
\text { no Ensino Fundamental e Médio. } \\
\text { A.M. de Amorim Madureira } \\
\text { (Dissertação. Universidade } \\
\text { Federal de Mato Grosso. 2019) }\end{array}$ & E1/ D4 & $\begin{array}{l}\text { EF, } \\
\text { EM }\end{array}$ \\
\hline $\begin{array}{l}\text { 102. Astronomia como disciplina } \\
\text { integradora para o ensino de } \\
\text { ciências. D.E. Peixoto (Tese. } \\
\text { Universidade Estadual de } \\
\text { Campinas. 2018) }\end{array}$ & $\begin{array}{l}\text { E1/ D4, } \\
\text { D6 }\end{array}$ & EM \\
\hline $\begin{array}{l}\text { 103. O Sol: Uma proposta de } \\
\text { Ensino. I. Gomes Varella } \\
\text { (Dissertação. Universidade de } \\
\text { São Paulo. 2017) }\end{array}$ & $\begin{array}{l}\text { E1, E2, } \\
\text { E3, E5/ } \\
\text { D3, D4, } \\
\text { D6 }\end{array}$ & $\begin{array}{l}\text { EF, } \\
\text { EM }\end{array}$ \\
\hline $\begin{array}{l}\text { 104. O aprendizado da } \\
\text { Astronomia e das ciências afins } \\
\text { com a medição da observação } \\
\text { rudimentar e da imagem } \\
\text { astronômica. C. Riegel Debom } \\
\text { (Dissertação. Universidade } \\
\text { Federal do Rio Grande do Sul. } \\
\text { 2010) }\end{array}$ & $\begin{array}{l}\mathrm{E} 1, \mathrm{E} 4 / \\
\mathrm{D} 5, \mathrm{D} 6\end{array}$ & EM \\
\hline $\begin{array}{l}\text { 105. Utilização de jogos } \\
\text { educativos como recurso no } \\
\text { processo de ensino de ciências } \\
\text { abordando tópicos de Astrofísica. } \\
\text { A.M. Stiz (Dissertação. } \\
\text { Universidade Federal de } \\
\text { Rondônia. 2017) }\end{array}$ & $\begin{array}{l}\mathrm{E} 1, \mathrm{E} 4 / \\
\mathrm{D} 2, \mathrm{D} 3 \\
\mathrm{D} 4\end{array}$ & EM \\
\hline
\end{tabular}

\begin{tabular}{|c|c|c|}
\hline $\begin{array}{l}\text { 106. Astronomia no Ensino } \\
\text { Médio: um mini planetário como } \\
\text { recurso instrucional para a } \\
\text { compreensão da dinâmica celeste. } \\
\text { D. dos Santos Leão (Dissertação. } \\
\text { Universidade de Brasília. 2012) }\end{array}$ & $\begin{array}{l}\text { E1, E4/ } \\
\text { D3, D4 }\end{array}$ & EM \\
\hline $\begin{array}{l}\text { 107. Elaboração de uma sequência } \\
\text { didática sobre conceitos de Fúsica } \\
\text { Moderna e Contemporânea num } \\
\text { DVD. P. Malicka Musiau } \\
\text { (Dissertação. Universidade } \\
\text { Federal de Rondônia. 2015) }\end{array}$ & $\begin{array}{l}\text { E1, E4, } \\
\text { E5/ D3, } \\
\text { D4 }\end{array}$ & EM \\
\hline $\begin{array}{l}\text { 108. Práticas de observação } \\
\text { astronômica no Ensino Médio: } \\
\text { uma proposta de sequência } \\
\text { didática para o uso de telescópio } \\
\text { remoto. V. Souza Lyra } \\
\text { (Dissertação. Universidade } \\
\text { Federal de São Carlos. 2020). }\end{array}$ & $\begin{array}{l}\mathrm{E} 1, \mathrm{E} 4 / \\
\mathrm{D} 3, \mathrm{D} 4 \\
\mathrm{D} 5, \mathrm{D} 6\end{array}$ & $\mathrm{EF}$ \\
\hline $\begin{array}{l}\text { 109. Concepção de um Manual } \\
\text { Escolar destinado ao Ensino } \\
\text { Secundário "A Vida das Estrelas". } \\
\text { A.M. Leal Tavares (Dissertação. } \\
\text { Universidade do Porto. 1999) }\end{array}$ & $\begin{array}{l}\text { E1, E2, } \\
\text { E3, E5, } \\
\text { E6/ D1, } \\
\text { D3, D4 }\end{array}$ & EM \\
\hline $\begin{array}{l}\text { 110. Origem, evolução e morte } \\
\text { das estrelas: uma Sequência } \\
\text { Didática para os alunos do Ensino } \\
\text { Médio, W. Fernandes da Silva } \\
\text { (Dissertação. Universidade } \\
\text { Federal do ABC. } 2016 \text { ) }\end{array}$ & $\begin{array}{l}\text { E1-E6/ } \\
\text { D1, D4 }\end{array}$ & EM \\
\hline $\begin{array}{l}\text { 111. Caixa Experimentoteca: uma } \\
\text { proposta para o Ensino de } \\
\text { Astronomia. E. Piza Perez } \\
\text { (Dissertação. Universidade } \\
\text { Estadual Paulista. 2015) }\end{array}$ & E1/ D4 & $\mathrm{EF}$ \\
\hline
\end{tabular}

Tabela A2: Artigos da Categoria E2.

\begin{tabular}{|l|l|l|}
\hline Obra & Cat.-Foco & N.Educ. \\
\hline - J.E. Horvath, op. cit. \#1 & & \\
\hline - F. Duarte Calado e H. Luz & & \\
Oliveira, op. cit. \#2 & & \\
\hline - A.A. Pereira Beloni, op. cit. \#3 & & \\
\hline - T.C. Caetano e G. Hickel, op. & & \\
cit \#6 & & \\
\hline - G.F. Marranghello e D.B. & & \\
Pavani, op. cit. \#9 & \\
\hline - V. Pereira de Barros, A. Braga & & \\
Oliveira, M. Bragagnolo e A.L. \\
D. Moreau, op. cit \#11 & & \\
\hline - Queiroz Agostinelli Ribeiro, op. & & \\
cit. \#15 & & \\
- R. Assenso, op. cit. \#20 & & \\
\hline - E. Freitas Moraes Borges, P.H. & & \\
de Azevedo Sobreira e J. & & \\
P.Machado Ribeiro, op. cit. \#22 & & \\
- M.A. Amorim, D. Alves de & & \\
Farias, E.M. dos Anjos, E.C. & & \\
Viana Nascimento e W.F. da & & \\
Silva, op. cit. \#26 & & \\
- H.D. Navone, M. Scancich e & & \\
R.A.Vázquez, op. cit. \#29 & & \\
- G. Iachel, op. cit. \#30 & & (Continued) \\
\hline
\end{tabular}


Tabela A2: Continued

\begin{tabular}{|c|c|c|}
\hline \multirow{3}{*}{$\begin{array}{l}\text { Obra } \\
\text { • D.I. Machado, op. cit. \#33 } \\
\text { - R. Kalbusch Saito e R. Baptista, } \\
\text { op. cit. \#34 }\end{array}$} & Cat.-Foco & N.Educ. \\
\hline & & \\
\hline & & \\
\hline $\begin{array}{l}\text { - A.A. de Souza e A.R. Valio, op. } \\
\text { cit. } \# 42\end{array}$ & & \\
\hline $\begin{array}{l}\text { - R.S. Levenhagen e R. Künzel, op. } \\
\text { cit. \#43 }\end{array}$ & & \\
\hline $\begin{array}{l}\text { D.C. Nardo Elias e M.S.T. } \\
\text { Araújo, op. cit. \#50 }\end{array}$ & & \\
\hline $\begin{array}{l}\text { - T.C. Caetano e W.S. Dias, op. } \\
\text { cit. \#54 }\end{array}$ & & \\
\hline $\begin{array}{l}\text { - G. Iachel, R.M.F. Scalvi e R. } \\
\text { Nardi, op. cit. \#55 }\end{array}$ & & \\
\hline $\begin{array}{l}\text { - A.T. Mota, R. Meloni, M. Rosado } \\
\text { e N.Figueiredo, op. cit. \#56 }\end{array}$ & & \\
\hline $\begin{array}{l}\text { K.N. Skolimoski, J.N. Teixeira e } \\
\text { M.P. Allen, op. cit. \#57 }\end{array}$ & & \\
\hline $\begin{array}{l}\text { - S.S. Moraes, J.R. Sabino e } \\
\text { L.G.R. Gonzaga, op. cit. \#58 }\end{array}$ & & \\
\hline $\begin{array}{l}\text { - R.F. Pereira, P.A. Fusinato, M.C. } \\
\text { Danhoni e M.C. Batista, op. cit. } \\
\text { \#62 }\end{array}$ & & \\
\hline $\begin{array}{l}\text { - M. Alencar de Souza e M. } \\
\text { Martins Marciel, op. cit. \#71 }\end{array}$ & & \\
\hline - J. Moura Aguiar, op. cit. \#77 & & \\
\hline $\begin{array}{l}\text { J.R.F. de Oliveira, E. dos R. } \\
\text { Nunes, R.B. Strieder e D.A. } \\
\text { Soares, op. cit. \#80 }\end{array}$ & & \\
\hline $\begin{array}{l}\text { - D.E. Peixoto e U. Kleinke, op. } \\
\text { cit. \#83 }\end{array}$ & & \\
\hline $\begin{array}{l}\text { J. de Paula Neves e M.D. } \\
\text { Moreira, op. cit. \# } 86\end{array}$ & & \\
\hline $\begin{array}{l}\text { - J. Santos, M. Deorce, A. Silva e } \\
\text { R. Santos, op. cit. \#87 }\end{array}$ & & \\
\hline $\begin{array}{l}\text { - M.L. Castanheira e D.W. Foryta, } \\
\text { op. cit. \#88 }\end{array}$ & & \\
\hline - E.C. Ferreira, op. cit. \#92 & & \\
\hline - T. Nunes Cestari, op. cit. \#93 & & \\
\hline - Machado Müller, op. cit. \#94 & & \\
\hline - E.L. da Cunha, op. cit. \#95 & & \\
\hline - T.A.J. Napoleão, op. cit. \#96 & & \\
\hline - Gomes Varella, op. cit. \#103 & & \\
\hline - A.M. Leal Tavares, op. cit. \#109 & & \\
\hline $\begin{array}{l}\text { - W. Fernandes da Silva, op. cit. } \\
\# 110 .\end{array}$ & & \\
\hline $\begin{array}{l}\text { 112. A contextualização da } \\
\text { Estrutura e Evoluçâa Estelar no } \\
\text { ensino da Termodinâmica como } \\
\text { ferramenta motivadora dos alunos. } \\
\text { J. Torres Lima e D.B. Pavani. Atas } \\
\text { do III SNEA (Curitiba, 2014) }\end{array}$ & $\begin{array}{l}\mathrm{E} 2, \mathrm{E} 3 / \\
\mathrm{D} 4, \mathrm{D} 5\end{array}$ & EM \\
\hline $\begin{array}{l}\text { 113. Espectroscopia: tirando a } \\
\text { carteira de identidade. L. de } \\
\text { Almeida Prata. Atas do I SNEA } \\
\text { (Rio de Janeiro, 2011) }\end{array}$ & $\mathrm{E} 2 / \mathrm{D} 4$ & $\begin{array}{l}\text { EM, } \\
\text { ES }\end{array}$ \\
\hline $\begin{array}{l}\text { 114. O equilíbrio e a estrutura } \\
\text { estelar em uma abordagem simples: } \\
\text { a Seqüência Principal. M. } \\
\text { Bandecchi, P.S. Bretones e J.E. } \\
\text { Horvath, RBEF 41, (2019) }\end{array}$ & E2/ D3 & EM \\
\hline
\end{tabular}

\begin{tabular}{|c|c|c|}
\hline $\begin{array}{l}\text { 115. O equilíbrio estelar e a } \\
\text { existência de uma massa máxima } \\
\text { para as estrelas. M.Bandecchi, } \\
\text { J.E. Horvath e P.S. Bretones, } \\
\text { RBEF } 41,(2019)\end{array}$ & E2/D1 & EM \\
\hline $\begin{array}{l}\text { 116. Una estrella bien simple. A. } \\
\text { Aceña, RBEF } 42,(2020)\end{array}$ & $\mathrm{E} 2 / \mathrm{D} 1$ & EM \\
\hline $\begin{array}{l}\text { 117. Esferas de gás em estado de } \\
\text { equilíbrio sob ação da gravitação } \\
\text { própria. A. Smirnov e R.M.M. } \\
\text { Oliveira, RBEF } 37,1308 \text { (2015) }\end{array}$ & E2/D1 & $\mathrm{ES}$ \\
\hline $\begin{array}{l}\text { 118. Uma abordagem didática da } \\
\text { natureza dos processos de } \\
\text { aquecimento da atmosfera } \\
\text { estelar. O.R. Nelson, RBEF } 35,1 \\
(2013)\end{array}$ & E2/ D1 & $\mathrm{ES}$ \\
\hline $\begin{array}{l}\text { 119. O Ensino de Astronomia por } \\
\text { meio das Tecnologias da } \\
\text { Informação e Comunicação. B.C. } \\
\text { Braga Camargo e S. Camargo. } \\
\text { Atas do XX SNEF (São Paulo, } \\
\text { 2013) }\end{array}$ & $\begin{array}{l}\mathrm{E} 2, \mathrm{E} 3 / \\
\mathrm{D} 3\end{array}$ & EM \\
\hline $\begin{array}{l}\text { 120. Assim na Terra como no } \\
\text { céu: a teoria do dínamo como } \\
\text { uma ponte entre o } \\
\text { geomagnetismo e o magnetismo } \\
\text { estelar. O.R. Nelson e J.R. De } \\
\text { Medeiros, RBEF } 34,1(2012)\end{array}$ & E2/D1 & $\mathrm{ES}$ \\
\hline $\begin{array}{l}\text { 121. Astronomia e as Tecnologias } \\
\text { de Informação e Comunicação } \\
\text { na Formação Inicial do } \\
\text { professor. M.R. Voelzke. Atas do } \\
\text { XX SNEF (São Paulo, 2013) }\end{array}$ & $\begin{array}{l}\mathrm{E} 2, \mathrm{E} 3 / \\
\mathrm{D} 2, \mathrm{D} 4\end{array}$ & $\begin{array}{l}\mathrm{EF}, \\
\mathrm{EM}\end{array}$ \\
\hline $\begin{array}{l}\text { 122. Astrofísica Estelar para o } \\
\text { Ensino Médio: análise de uma } \\
\text { proposta. M.B. da Fonseca Vieira } \\
\text { (Dissertação. Universidade de } \\
\text { São Paulo. 2018) }\end{array}$ & $\begin{array}{l}\mathrm{E} 2, \mathrm{E} 3 \\
\mathrm{E} 5, \mathrm{E} 6 / \\
\mathrm{D} 3, \mathrm{D} 4\end{array}$ & $\mathrm{EM}$ \\
\hline $\begin{array}{l}\text { 123. Análise qualitativa de uma } \\
\text { sequência didática (SD): Ensino } \\
\text { de Astrofísica Estelar para alunos } \\
\text { do Ensino Médio. K. Brasil } \\
\text { Neves (Dissertação. Universidade } \\
\text { de São Paulo. 2020). }\end{array}$ & $\begin{array}{l}\mathrm{E} 2, \mathrm{E} 3 \\
\mathrm{E} 5, \mathrm{E} 6 / \\
\mathrm{D} 3, \mathrm{D} 4\end{array}$ & EM \\
\hline $\begin{array}{l}\text { 124. Tópicos de Astrofísica e } \\
\text { Cosmologia: uma aplicação da } \\
\text { Fúsica Moderna e } \\
\text { Contemporânea no Ensino } \\
\text { Médio. R. Rechi Aguiar } \\
\text { (Dissertação. Universidade de } \\
\text { São Paulo. 2010). }\end{array}$ & $\begin{array}{l}\text { E2, E3, } \\
\text { E5, E6/ } \\
\text { D3, D4, } \\
\text { D5 }\end{array}$ & EM \\
\hline $\begin{array}{l}\text { 125. Astrofísica de estrelas } \\
\text { compactas como atividades } \\
\text { suplementar para o Ensino } \\
\text { Médio. J.C. Feital Frazzoli } \\
\text { (Dissertação. Universidade } \\
\text { Federal do Rio de Janeiro. 2012). }\end{array}$ & $\begin{array}{l}\text { E2, E3, } \\
\text { E5, E6/ } \\
\text { D2, D3, } \\
\text { D4 }\end{array}$ & EM \\
\hline $\begin{array}{l}\text { 126. Construção do diagrama } \\
\text { Hertzsprung-Russel através do } \\
\text { Stellarium: uma proposta para } \\
\text { explorar conceitos de Física } \\
\text { Moderna e Contemporânea no } \\
\text { Ensino Médio. M. Girardi }\end{array}$ & $\begin{array}{l}\text { E2, E3, } \\
\text { E6/ D3, } \\
\text { D4 }\end{array}$ & EM \\
\hline
\end{tabular}


Tabela A2: Continued

\begin{tabular}{|l|l|l|}
\hline Obra & Cat.-Foco & N.Educ. \\
\hline (Dissertação. Universidade & & \\
Federal do Rio Grande do Sul. & & \\
2017) & & \\
\hline 127. Material didático sobre a & E2/ D2, & EM \\
dinâmica dos campos magnéticos & D4 & \\
do Sol. R. Nunes da Costa (TCC. & & \\
Universidade de Brasília. 2014) & & \\
\hline 128. Evolução Estelar no Ensino & E2, E3, & EF, \\
de Ciências. A. Bastos da Silva & E5, E6/ & EM \\
(Dissertação. Universidade & D3, D4, & \\
Estadual de Feira de Santana. & D5 & \\
2017.) & & \\
\hline 129. Formação e evolução estelar & E2, E3, & EM \\
como uma proposta de & E5, E6/ & \\
contextualização para o ensino de & D2, D3, & \\
Termodinâmica no Ensino & D4, D5 & \\
Médio. R. da Silva Rosa & & \\
Rodrigues (Dissertação. & & \\
Universidade Federal de Santa & & \\
Catarina. 2016) & & \\
\hline 130. DYNAMIS: jogo de & E2/ D3 & EM \\
tabuleiro para introdução de & & \\
termodinâmica no Ensino Médio. & & \\
B. Medeiros Quaresma. & & \\
(Dissertação. Universidade & & \\
Federal do Sul e Sudeste do & & \\
Pará, 2020) & & \\
\hline 131. As linhas fronteiriças dos \\
constituintes da matéria. D. & E2, E3/ & ES \\
Galetti e S.S. Mizrahi, RBEF 41, \\
(2019) & & \\
\hline 132. Análise de conteúdos de \\
física nuclear em livros escolares & D2, E3/ & EM \\
brasileiros, A. Tenório, L. Souza \\
Quintana, W. Vallory Nunes e T. \\
Tenório. REEC 14, 175 (2015) & & \\
& & \\
\hline
\end{tabular}

Tabela A3: Artigos da Categoria E3.

\begin{tabular}{|l|l|l|}
\hline Obra & Cat.-Foco & N.Educ. \\
\hline - J.E. Horvath, op. cit. \#1 & & \\
\hline - F. Duarte Calado e H. Luz & & \\
Oliveira, op. cit. \#2 & & \\
\hline - A.A. Pereira Beloni, op. cit. \#3 & & \\
\hline $\begin{array}{l}\text { - T.C. Caetano e G. Hickel, op. } \\
\text { cit. \#6 }\end{array}$ & & \\
\hline - G.F. Marranghello e D. B. & & \\
Pavani, op. cit. \#9 & & \\
\hline - V. Pereira de Barros, A. Braga & & \\
Oliveira, M. Bragagnolo e A.L. & & \\
D. Moreau, op. cit. \#11 & & \\
\hline - Queiroz Agostinelli Ribeiro, op. & & \\
cit. \#15 & & \\
\hline - R. Assenso, op. cit. \#20 & & \\
\hline - E.F. Moraes Borges, P.H. de & & \\
Azevedo Sobreira e J. & & \\
P.Machado Ribeiro, op. cit. \#22 & & \\
\hline - G. Iachel, op. cit. \#30 & & \\
\hline - D.I. Machado, op. cit.\#33 & & \\
\hline - R. Kalbusch Saito e R. & \\
Baptista, op. cit. \#34 & & \\
\hline - A.A. de Souza e A.R. Valio, op. \\
cit. \#42
\end{tabular}

- T.C. Caetano e W.S. Dias, op. cit. \#54

- G. Iachel, R.M.F. Scalvi e R. Nardi, op. cit. \#55

- A.T. Mota, R. Meloni, M. Rosado e N.Figueiredo, op. cit. \#56

- S.S. Moraes, J.R. Sabino e

L.G.R. Gonzaga, op. cit. \#58

- R.M.M. Rosado, op. cit. \#60

- C. Alencar de Souza e A. M. Martins Marciel., op. cit. \#71

- J. Moura Aguiar, op. cit. \#77

- J.R.F. de Oliveira, E. dos R. Nunes, R.B. Strieder e D.A. Soares, op. cit. \#80

- M.S. Kitagawa, op. cit. \#81

- D.E. Peixoto e U. Kleinke, op. cit. \#83

- R. Lopes, P. Assunção, T. Maciel, P. Gontijo e E. Rodrigues, op. cit. \#85

- J. de Paula Neves e M.D. Moreira, op. cit. \#86

- J. Santos, M. Deorce, A. Silva e R. Santos, op. cit. \#87

- M.B. da Fonseca Vieira, op. cit. \#122

133. Um jogo de RPG para ensinar sobre Astrofísica. F.L. Rommel e V. Scheibel. Atas do XXII SNEF. (São Carlos, 2017)

134. Anãs brancas para o Ensino Médio. V.C. de Sales. Atas do XIX SNEF (Manaus, 2011)

135. A utilização do software Maxima no ensino por investigação da evolução estelar utilizando simulação gráfica da fusão nuclear. A.C. Sabino et al. RBEF 41, (2019)

\section{Variáveis Cefeidas e a} contribuição feminina na ciência: recursos para o ensino de oscilações, ondas e óptica. E. Ferreira Santos (Dissertação. Universidade Federal de Sergipe. 2016)

Tabela A4: Artigos da Categoria E4.

\begin{tabular}{|c|c|c|}
\hline Obra & Cat.-Foco & N.Educ. \\
\hline $\begin{array}{l}\text { - D.E. Peixoto e E.M. de França } \\
\text { Ramos, op. cit\#4 }\end{array}$ & & \\
\hline $\begin{array}{l}\text { - T.C. Caetano e G. Hickel, op. } \\
\text { cit. \#6 }\end{array}$ & & \\
\hline $\begin{array}{l}\text { - M. Lopes Pinheiro, V. Queiroz } \\
\text { e Daniel Trevisan Sanzovo, op. } \\
\text { cit. \#10 }\end{array}$ & & \\
\hline $\begin{array}{l}\text { - V. Pereira de Barros, A. Braga } \\
\text { Oliveira, M. Bragagnolo e A.L. } \\
\text { D. Moreau, op. cit. \#11 }\end{array}$ & & \\
\hline $\begin{array}{l}\text { - L.L. Ducheiko, J.A. Parrilha da } \\
\text { Silva e M.C. Danhoni Neves, } \\
\text { op. cit. \#13 }\end{array}$ & & \\
\hline
\end{tabular}


Tabela A4: Continued

\begin{tabular}{|c|c|c|}
\hline Obra & Cat.-Foco & N.Educ. \\
\hline $\begin{array}{l}\text { - M. de Souza Rodrigues e C. } \\
\text { Leite, op. cit. \#19 }\end{array}$ & & \\
\hline $\begin{array}{l}\text { - A.R. Barreda e R.K. Kimura, } \\
\text { op. cit. \#23 }\end{array}$ & & \\
\hline - G. Iachel, op. cit. \#30 & & \\
\hline $\begin{array}{l}\text { - R.K. Kimura e L.P. Piassi, op. } \\
\text { cit. \#32 }\end{array}$ & & \\
\hline - D.B. de Freitas, op. cit. \#48 & & \\
\hline $\begin{array}{l}\text { - C. Leite e Y. Hossume, op. cit. } \\
\text { \#49 }\end{array}$ & & \\
\hline $\begin{array}{l}\text { - M.M. da Silva, J.M. Hidalgo } \\
\text { Ferreira, J.D. dos Santos Nicácio } \\
\text { e D.S. Fonseca, op. cit. \#74 }\end{array}$ & & \\
\hline $\begin{array}{l}\text { - A.L. de Moura Pessoa, G.R. } \\
\text { Pessôa Campello Queiroz e J.C. } \\
\text { dos Santos Moreira, op. cit. \#84 }\end{array}$ & & \\
\hline $\begin{array}{l}\text { - C. Leite e Y. Hossume, op. cit. } \\
\text { \#89 }\end{array}$ & & \\
\hline - P.S. Bretones, op. cit. \#99 & & \\
\hline - C. Riegel Debom, op. cit. \#104 & & \\
\hline - A.M. Stiz, op. cit. \#105 & & \\
\hline $\begin{array}{l}\text { - D. dos Santos Leão, op. cit. } \\
\# 106\end{array}$ & & \\
\hline - P. Malicka Musiau, op. cit. \#107 & & \\
\hline - V. Souza Lyra, op. cit. \#108 & & \\
\hline $\begin{array}{l}\text { - W. Fernandes da Silva, op. cit. } \\
\# 110\end{array}$ & & \\
\hline $\begin{array}{l}\text { - T.F. Genzini de Carvalho e } \\
\text { J. Lopes de Almeida Pacca, op. } \\
\text { cit. \#16 }\end{array}$ & & \\
\hline $\begin{array}{l}\text { 137. Uma proposta de discussão de } \\
\text { controvérsias históricas e } \\
\text { epistemológicas acerca da } \\
\text { Evolução Estelar para o Ensino } \\
\text { Médio. B. Lopes da Costa, F. } \\
\text { Polati e M.P. Allen. Atas do V } \\
\text { SNEA (Londrina, 2018) }\end{array}$ & $\begin{array}{l}\text { E4/ D3, } \\
\text { D6 }\end{array}$ & EM \\
\hline $\begin{array}{l}\text { 138. Astronomia Cultural nos } \\
\text { ensinos Fundamental e Médio. } \\
\text { L.C. Jafelice. RELEA 19, } 57 \\
(2015)\end{array}$ & $\begin{array}{l}\text { E4/ D1, } \\
\text { D3 }\end{array}$ & $\begin{array}{l}\text { EF, } \\
\text { EM. }\end{array}$ \\
\hline $\begin{array}{l}\text { 139. A construção de conceitos } \\
\text { sobre a pequenez humana: } \\
\text { Astronomia em aulas de Filosofia } \\
\text { no Ensino Médio. C. A. do } \\
\text { Nascimento e P.S. Bretones. Atas } \\
\text { do V SNEA (Londrina, 2018) }\end{array}$ & $\begin{array}{l}\text { E4/ D1, } \\
\text { D6 }\end{array}$ & EM \\
\hline $\begin{array}{l}\text { 140. Os limpiadores de estrelas: o } \\
\text { conto de literatura fantástica no } \\
\text { Ensino de Física. J.E. Fernandes } \\
\text { Ramos e L.P. Piassi, Atas do I } \\
\text { SNEA (Rio de Janeiro, 2011) }\end{array}$ & $\mathrm{E} 4 / \mathrm{D} 3$ & $\begin{array}{l}\mathrm{EF}, \\
\mathrm{EM}\end{array}$ \\
\hline $\begin{array}{l}\text { 141. Astronomia e cultura nas } \\
\text { pesquisas em Ensino das Ciências } \\
\text { na última década. V. } \\
\text { Albuquerque, C. Merlucci, M. } \\
\text { Rodrigues e C. Leite. Atas do I } \\
\text { SNEA (Rio de Janeiro, 2011) }\end{array}$ & $\mathrm{E} 4 / \mathrm{D} 1$ & $\mathrm{ES}$ \\
\hline $\begin{array}{l}\text { 142. Uma proposta para a inclusão } \\
\text { de tópicos de astronomia indígena } \\
\text { brasileira nas aulas de Física do } \\
\text { Ensino }\end{array}$ & $\mathrm{E} 4 / \mathrm{D} 1$ & EM \\
\hline
\end{tabular}

Médio. D.C. de Araújo, M.F. da Silva Verdeaux e W.T. Cardoso. Ciênc. Educ. 23, 1035 (2017)

143. Educação em Astronomia: investigando aspectos de conscientização socioambiental sobre a poluição luminosa na perspectiva da abordagem temática. F.A. de Oliveira e R. Langhi. Ciênc. Educ. 20, 653 (2014)

144. Ensino de Física com

histórias em quadrinhos: o astronauta em Magnetar. G. Ferraz de Barros (TCC. Universidade Estadual Paulista. 2015).

145. Análise sobre conhecimento gerais de Astronomia e Astrofísica entre Universitários e pessoas em geral da região de Ariquemes-RO. R. Lima Gomes (TCC. Faculdade de Educação e Meio Ambiente. 2013).

146. Proposta de um minicurso de Astronomia para alunos do Ensino Fundamental II. L.

Carnevarolo Pesquero

(Dissertação. Universidade Federal de São Carlos. 2015).

147. Desenvolvimento de material didático de apoio de Astronomia para professores do segundo ciclo do Ensino Fundamental. S. Hiller (Dissertação. Universidade Tecnológica Federal do Paraná. 2016)

148. Textos de divulgação

científica no ensino de

Astronomia: Produção,

divulgação e aplicação. A. I.

Sunaga (Dissertação.

Universidade de São Paulo. 2018)

149. Um estudo sobre a formação continuada de professores da educação básica para o ensino de Astronomia utilizando o "Diário do céu" como estratégia de ensino. T.C. Dias Fernandes (Tese. Universidade Estadual Paulista. 2018)

150. Tópicos em Astronomia no primeiro ano do Ensino Médio.

D. Flach (Dissertação.

Universidade Federal do Rio

Grande do Sul. 2018)

151. Um projeto de intervenção nos espaços de exposição do planetário do Parque Ibirapuera. D.C. Nardo Elias (Dissertação. Universidade Cruzeiro do Sul. 2006)

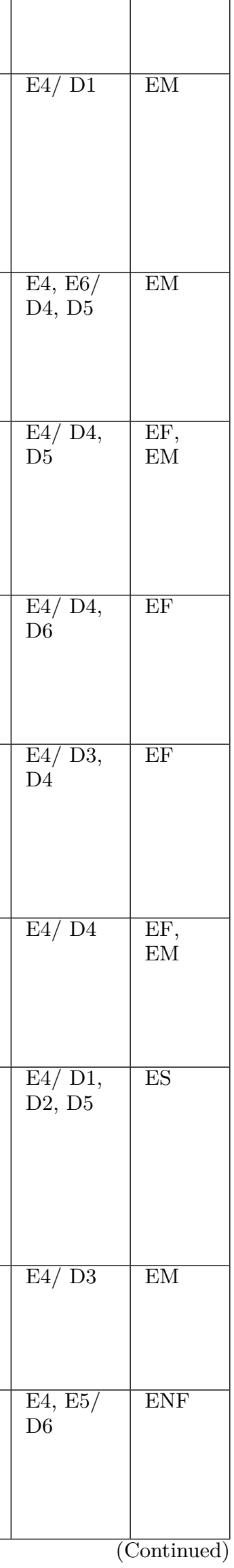


Tabela A4: Continued

\begin{tabular}{|l|l|l|}
\hline Obra & Cat.-Foco & N.Educ. \\
\hline $\begin{array}{l}\text { 152. O presente das estrelas: o } \\
\text { encontro da literatura infantil } \\
\text { com a Astronomia. L. Rogatto e }\end{array}$ & D4, D3 & EF \\
$\begin{array}{l}\text { Silva (Dissertação. Universidade } \\
\text { Estadual de Campinas. 2014) }\end{array}$ & & \\
\hline $\begin{array}{l}\text { 153. O objetivo das visitas } \\
\text { escolares a um observatório } \\
\text { astronômico na visão dos } \\
\text { professores. F.R. da Costa }\end{array}$ & E4/ D2, & ES \\
$\begin{array}{l}\text { Linhares (Dissertação. } \\
\text { Universidade Federal de Minas } \\
\text { Gerais. 2011) }\end{array}$ & & \\
\hline $\begin{array}{l}\text { 154. O ensino de ciências em } \\
\text { planetários: perspectivas } \\
\text { interdisciplinares sobre as sessões } \\
\text { de cúpula. G. Maia de Oliveira } \\
\text { (Dissertação. Universidade }\end{array}$ & D4/ D5, & ENF \\
Cruzeiro do Sul. 2010) & & \\
\hline
\end{tabular}

Tabela A5: Artigos da Categoria E5.

\begin{tabular}{|c|c|c|}
\hline Obra & Cat.-Foco & N.Educ. \\
\hline $\begin{array}{l}\text { - T.C. Caetano e G. Hickel, op. } \\
\text { cit. \#6 }\end{array}$ & & \\
\hline $\begin{array}{l}\text { - Queiroz Agostinelli Ribeiro, op. } \\
\text { cit. \#15 }\end{array}$ & & \\
\hline - G. Iachel, op. cit. \#30 & & \\
\hline - J. Moura Aguiar, op. cit. \#77 & & \\
\hline $\begin{array}{l}\text { - T.I. Gonçalves do Carmo, op. } \\
\text { cit. \#91 }\end{array}$ & & \\
\hline - I. Gomes Varella, op. cit. \#103 & & \\
\hline - P. Malicka Musiau, op. cit. \#107 & & \\
\hline - A.M. Leal Tavares, op. cit. \#109 & & \\
\hline $\begin{array}{l}\text { - W. Fernandes da Silva, op. cit. } \\
\# 110\end{array}$ & & \\
\hline $\begin{array}{l}\text { - M.B. da Fonseca Vieira, op. cit. } \\
\quad \# 122\end{array}$ & & \\
\hline - K. Brasil Neves, op. cit. \#123 & & \\
\hline - R. Rechi Aguiar, op. cit. \#124 & & \\
\hline $\begin{array}{l}\text { - J.C. Feital Frazzoli, op. cit. } \\
\# 125\end{array}$ & & \\
\hline - A. Bastos da Silva, op. cit. \#128 & & \\
\hline $\begin{array}{l}\text { - R. da Silva Rosa Rodrigues, op. } \\
\text { cit. \#134 }\end{array}$ & & \\
\hline - D.C. Nardo Elias, op. cit. \#151 & & \\
\hline $\begin{array}{l}\text { 155. Fractalidad en regiones de } \\
\text { Formación Estelar. H.E. } \\
\text { Caicedo-Ortiz, H.O. Castañeda e } \\
\text { E. Santiago-Cortés, RBEF } 39, \\
(2017)\end{array}$ & E5/ D1 & ES \\
\hline $\begin{array}{l}\text { 156. Subsídios para uma discussão } \\
\text { da formação das estrelas na sala } \\
\text { de aula. J.E. Horvath, RBEF } 43 \text {, } \\
\text { e20210237 (2021) }\end{array}$ & $\mathrm{E} 5 / \mathrm{D} 1$ & ES \\
\hline
\end{tabular}

Tabela A6: Artigos da Categoria E6.

\begin{tabular}{|l|l|l|}
\hline Obra & Cat.-Foco & N.Educ. \\
\hline $\begin{array}{l}\text { - T.C. Caetano e G. Hickel, op. } \\
\text { cit. \#6 }\end{array}$ & & \\
\hline $\begin{array}{l}\text { - Queiroz Agostinelli Ribeiro, op. } \\
\text { cit. \#15 }\end{array}$ & & \\
\hline
\end{tabular}

- G. Iachel, op. cit. \#30

- J.M. Rodríguez, op. cit. \#46

- R.M.M. Rosado, op. cit. \#60

- J. Moura Aguiar, op. cit. \#77

- A.M. Leal Tavares, op. cit. \#109

- W. Fernandes da Silva, op. cit. \#110

- M.B. da Fonseca Vieira, op. cit. \#122

- K. Brasil Neves, op. cit. \#123

- R. Rechi Aguiar, op. cit. \#124

- J.C. Feital Frazzoli, op. cit. \#125

- M. Girardi, op. cit. \#126

- A. Bastos da Silva, op. cit. \#128

- R. da Silva Rosa Rodrigues, op. cit. \#129

- V.C. de Sales, op. cit. \#134

- G. Ferraz de Barros, op. cit. \#144

157. Michell, Laplace e as estrelas negras: uma abordagem para professores do Ensino

Médio. R.R. Machado e A.C.

Tort, RBEF 38, 0017 (2016)

158. Astronomia no Ensino

Médio: uma abordagem

simplificada a partir da teoria da

Relatividade Geral. R. V. Lessa do

Couto. (Dissertação. Universidade

de Brasília. 2020)

159. Os conceitos da Teoria da

Relatividade com utilização do

Ensino Sob Medida. G. H. Garcia.

(Dissertação. Universidade

Federal do ABC. 2019)

160. A utilizaçấo do filme

Interestelar para o ensino de

Física Moderna no Ensino Médio.

L.F. de Melo, D.F. Rodrigues,

R.C. de Castro, C. J. Ferreira,

A.N.S. Farias, C. de F. B. de

Oliveira e T.S.O. Alvez. Atas do

XXII SNEF (São Carlos, 2017)

161. Uma introdução às estrelas

estranhas. V.P. Gonçalves e L. da

Silva Lazzari, RBEF 42,0032

(2020)

162. A pré-história dos buracos

negros. C.R. Almeida, RBEF 42,

0197 (2020)

163. A massa máxima das estrelas

de nêutrons: uma abordagem

didática. J.E. Horvath, RBEF 42,

0240 (2020)

164. Dedução do limite de

Chandrasekhar: uma abordagem

didática dos trabalhos originais do

autor. E.F.D. Evangelista, RBEF

41, 0167 (2019)

165. Resenha-Buracos negros:

palestras da BBC Reith

Lectures. J.L.P. Ribeiro, RBEF

39, 0043 (2019)

\begin{tabular}{|l|l|l|}
\hline & & \\
\hline & & \\
\hline & & \\
\hline & & \\
\hline & & \\
\hline & & \\
\hline
\end{tabular}

\begin{tabular}{|l|l|}
\hline & \\
\hline & \\
\hline
\end{tabular}

\begin{tabular}{|l|l|}
\hline & \\
\hline
\end{tabular}

\begin{tabular}{|l|l}
\hline & \\
\hline & \\
\hline & \\
\hline
\end{tabular}

E6/ D6 EM

E6/ D1, $\quad$ EM

D3

E6/ D3, EM

D4

E6/ D1, EM

D3

D

E6/ D1 ES

E6/ D6 ES

E6/ D1 ES

E6/ D1 ES

E6/ D4 EM,

ENF 
Tabela A6: Continued

\begin{tabular}{|l|l|l|}
\hline Obra & Cat.-Foco & N.Educ. \\
\hline 166. Cem anos de buracos negros: & $\mathrm{E} 6 / \mathrm{D} 1$ & $\mathrm{ES}$ \\
o centenário da solução de & & \\
Schwarzschild. A.Saa, RBEF 38, & & \\
0191 (2016) & & \\
\hline 167. Uma possibilidade de leitura & $\mathrm{E} 6 / \mathrm{D} 1$, & $\mathrm{EF}$, \\
no ensino de física: o tema & $\mathrm{D} 4$ & $\mathrm{EM}$, \\
buracos negros através de um & & $\mathrm{ENF}$ \\
livro de divulgação científica. F. & & \\
Marchi e C. Leite. Atas do XX & & \\
SNEF (São Paulo, 2013) & & \\
\hline $\begin{array}{l}\text { 168. O deslocamento de aspectos } \\
\text { do funcionamento do discurso } \\
\text { pedagógico pela leitura de textos }\end{array}$ & & \\
de divulgação científica em aulas & & \\
de Física. H. C. da Silva e & & \\
M.J.P.M. de Almeida. REEC 4, 3 & & \\
(2005) & & \\
\hline 169. Alguns aspectos da física de & E6/ D1, & EM \\
buracos negros através da & D3 & \\
modelagem matemática: uma & & \\
intervenção didática para o & & \\
ensino médio. V. H. Rangel de & & \\
Oliveira. (Dissertação. Instituto & & \\
Federal de Educação, Ciência e & & \\
Tecnologia Fluminense. 2017) & & \\
\hline
\end{tabular}

\section{Referências}

[1] J.E. Horvath, As estrelas na sala de aula (Ed. Livraria da Física, São Paulo, 2019).

[2] B. Russell, História do Pensamento Ocidental (Ed. Ediouro, Rio de Janeiro, 2001).

[3] J.E. Horvath, Rev. Bras. Ens. Fis. 35, 1 (2013).

[4] J. Lépine, A Via Láctea, nossa ilha no Universo (Ed. EDUSP, São Paulo, 2008).

[5] J. Megid Neto, Tendências da pesquisa acadêmica sobre o ensino de ciências no nivel fundamental. Tese de Doutorado, (Universidade Estadual de Campinas, Campinas, 1999).

[6] P.S. Bretones e J. Megid Neto, Boletim da Sociedade Astronômica Brasileira 24, 35 (2005).

[7] P.C. Gonçalves, P.S. Bretones e J.E. Horvath, Levantamento de Recursos Didáticos para o ensino de Cosmologia, Rev. Bras. Ens. Fis., no prelo (2021).

[8] A.R. Batista, A.P. Silva e J.R.N. Silva, Análise das tendências presentes nos trabalhos apresentados nas edições do Encontro Nacional de Pesquisa em Educação em Ciências (ENPEC) sobre o Ensino de Astronomia. Atas do XI ENPEC, Florianópolis, SC (2017).

[9] H.L.Tignanelli, em: Didática das Ciências naturais: contribuições e reflexões, editado por H. Weissmann (org.) (Ed. Artmed, Porto Alegre, 1998).

[10] C. Leite e Y. Hosoume, Revista Latino-Americana de Educação em Astronomia 4, 47 (2007)

[11] E. Costa Júnior, B.S. Fernandes, G.S. Lima, A.J. Siqueira, J.N.M. Paiva, M.G. Santos, J.P. Tavares, T.V. Souza e T.M.F. Gomes, Rev. Bras. Ens. Fis. 40, 4 (2018).
[12] INEP. Censo da Educação Básica 2019: Resumo Técnico, disponível em: http://portal.inep.gov.br/inf ormacao-da-publicacao/-/asset_publisher/6JYIsGM AMkW1/document/id/6874720, 2020.

[13] M. Giordan, Y.A.F. Guimarães e L. Massi. Encontro Nacional de Pesquisa em Educação em Ciências 8, 1 (2011).

[14] S.A. Almoloud e C. de Queiroz e Silva Coutinho, Rev. Elet. Edu. Mat. 3, 1 (2008).

[15] N. Soares e V.M. Guridi, Uma Sequência Didática para o ensino de Astronomia baseada na Teoria da Aprendizagem Significativa. Atas do II SNEA (São Paulo, 2012).

[16] A. Zabala. Como trabalhar os conteúdos procedimentais em aula (Ed. Artmed, Porto Alegre, 1999).

[17] J.C. Libâneo. Didática. (Cortez Editora, São Paulo, 1990).

[18] P. Lijnse, em: Designing theory-based teaching-learning sequences for Science education, Proceedings of the Symposium in honour of Piet Lijnse at the time of his retirement of Physics Didactics at Utrecht University, Eds. K. Klaasen e K. Kortland., p.91 (FIsme series on Research in Science Education 64; 2010)

[19] J. Leach, J. Ametller e P. Scott. em: Designing theorybased teaching-learning sequences for Science education. Proceedings of the Symposium in honour of Piet Lijnse at the time of his retirement of Physics Didactics at Utrecht University. Eds. K. Klaasen and K. Kortland., p.7 (FIsme series on Research in Science Education 64; 2010)

[20] A. Colantonio, S. Galano, S. Leccia, E. Puddu e I. Testa, Physical Review Physics Education Research 14, 010143. 2018.

[21] A. Fraknoi, em: The universe at your fingertips: an Astronomy USA Project Astro. Ch.1. Activity and resource notebook (1995).

[22] J.M. Pasachoff, Astronomy Education Review 1, 124 (2002).

[23] P.J. Camp, The Physics Teacher, 39, 516 (2001).

[24] M. Seeds, The Physics Teacher 39, 517 (2001). 